\title{
Systems of variational inequalities with hierarchical variational inequality constraints in Banach spaces
}

\author{
Lu-Chuan Cenga ${ }^{\mathrm{a}}$, Yeong-Cheng Liou ${ }^{\mathrm{b}, \mathrm{c}, *}$, Ching-Fen Wen ${ }^{\mathrm{d}}$ \\ a Department of Mathematics, Shanghai Normal University, and Scientific Computing Key Laboratory of Shanghai Universities, \\ Shanghai 200234, China. \\ ${ }^{b}$ Department of Healthcare Administration and Medical Informatics, and Research Center of Nonlinear Analysis and Optimization, \\ Kaohsiung Medical University, Kaohsiung 807, Taiwan. \\ ${ }^{c}$ Department of Medical Research, Kaohsiung Medical University Hospital, Kaohsiung 807, Taiwan. \\ ${ }^{d}$ Center for Fundamental Science, and Research Center for Nonlinear Analysis and Optimization, Kaohsiung Medical University, \\ Kaohsiung 807, Taiwan.
}

Communicated by $\mathrm{X}$. Qin

\begin{abstract}
Two implicit iterative algorithms are presented to solve a general system of variational inequalities with the hierarchical variational inequality constraint for an infinite family of nonexpansive mappings. Strong convergence theorems are given in a uniformly convex and 2-uniformly smooth Banach space. The results improve and extend the corresponding results in the earlier and recent literature. (C)2017 All rights reserved.
\end{abstract}

Keywords: Variational inequalities, nonexpansive mapping, fixed point, implicit iterative algorithm. 2010 MSC: 49J30, 47H09, 47J20, 49M05.

\section{Introduction}

Let $X$ be a real Banach space with its topological dual $X^{*}$, and $C$ be a nonempty closed convex subset of $X$. Let $T: C \rightarrow X$ be a nonlinear mapping on $C$. We denote by $\operatorname{Fix}(T)$ the set of fixed points of $T$ and by $\mathbf{R}$ the set of all real numbers. A mapping $T: C \rightarrow X$ is called L-Lipschitz continuous if there exists a constant $L \geqslant 0$ such that

$$
\|T x-T y\| \leqslant L\|x-y\|, \quad \forall x, y \in C .
$$

In particular, if $L=1$ then $T$ is called nonexpansive; if $L \in[0,1)$ then $T$ is said to be contractive.

The normalized dual mapping $\mathrm{J}: \mathrm{X} \rightarrow 2^{\mathrm{X}^{*}}$ is defined by

$$
\mathrm{J}(\mathrm{x}):=\left\{\varphi \in \mathrm{X}^{*}:\langle\varphi, x\rangle=\|x\|^{2}=\|\varphi\|^{2}\right\}, \quad \forall x \in X,
$$

\footnotetext{
*Corresponding author

Email addresses: zenglc@hotmail.com (Lu-Chuan Ceng), simplex_liou@hotmail.com (Yeong-Cheng Liou), cf wen@kmu . edu . tw (Ching-Fen Wen)

doi:10.22436/jnsa.010.06.28
} 
where $\langle\cdot, \cdot\rangle$ denotes the generalized duality pairing; see e.g., [12] for further details.

Let $U:=\{x \in X:\|x\|=1\}$ be the unit sphere of $X$. The space $X$ is said to have a Gâteaux differentiable

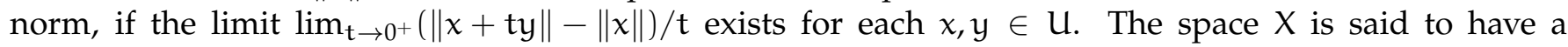
uniformly Gâteaux differentiable norm, if the limit is attained uniformly for $x \in U$. The space $X$ is said to be strictly convex if and only if for $x, y \in U$ with $x \neq y$, we have $\|(1-\lambda) x+\lambda y\|<1, \forall \lambda \in(0,1)$. It is well-known ([12]) that if $X$ is smooth, then the normalized duality mapping is single-valued; and if the norm of $X$ is uniformly Gâteaux differentiable, then the normalized duality mapping is norm to weak star uniformly continuous on every bounded subsets of $X$. In the sequel, we shall denote the single-valued normalized duality mapping by $j$.

Let $X$ be a smooth Banach space. Let $A, B: C \rightarrow X$ be two nonlinear mappings and $\lambda, \mu$ be two positive real numbers. The general system of variational inequalities (GSVI) is to find $\left(x^{*}, y^{*}\right) \in C \times C$ such that

$$
\begin{cases}\left\langle\lambda A y^{*}+x^{*}-y^{*}, J\left(x-x^{*}\right)\right\rangle \geqslant 0, & \forall x \in C, \\ \left\langle\mu \mathrm{B} x^{*}+y^{*}-x^{*}, J\left(x-y^{*}\right)\right\rangle \geqslant 0, & \forall x \in C .\end{cases}
$$

The equivalence between the GSVI (1.1) and the fixed point problem in a Banach space is established by Yao et al. [25]. The authors introduced two iterative algorithms for solving the GSVI (1.1) and proved the strong convergence of the sequences generated by the proposed algorithms. Subsequently, Ceng et al. [6] proposed Mann's type algorithms for solving GSVI (1.1). It is worth mentioning that the system of variational inequalities plays an important role in game theory and economics. Namely, the Nash equilibrium problem can be formulated in the form of variational inequality; see e.g., [1, 7] and the references therein.

Existing results. (1) If $X$ is a real Hilbert space, GSVI (1.1) was introduced and studied by Ceng et al. [10]. (2) If $A=B$, it was considered by Verma [22]. Further, in this case, when $x^{*}=y^{*}$, problem (1.1) reduces to the following classical variational inequality (VI) of finding $x^{*} \in \mathrm{C}$ such that

$$
\left\langle A x^{*}, x-x^{*}\right\rangle \geqslant 0, \quad \forall x \in C .
$$

This problem is a fundamental problem in the variational analysis, optimization theory, and mechanics; see e.g., $[8,11,17,24,29-31]$ and the references therein. A large number of algorithms for solving this problem are essentially projection algorithms that employ projections onto the feasible set C of the VI, or onto some related sets, so as to iteratively reach a solution. In particular, Korpelevich [16] proposed an algorithm for solving the VI in Euclidean space. This method further has been improved by several researchers; see e.g., $[13,19]$ and the references therein.

In the case of Banach space setting, that is, if $A=B$ and $x^{*}=y^{*}$, the VI is defined as

$$
\left\langle A x^{*}, j\left(x-x^{*}\right)\right\rangle \geqslant 0, \quad \forall x \in C .
$$

Aoyama et al. [2] proposed an iterative scheme to find the approximate solution of (1.2) and proved the weak convergence of the sequences generated by the proposed scheme. It is also well-known (see [2, Lemma 2.7]) that this problem in a smooth Banach space is equivalent to a fixed-point equation. In [32], Zeng and Yao introduced an implicit method that converges weakly to a solution of a variational inequality. Ceng et al. [9] extended the result from nonexpansive mappings to Lipschitz pseudocontractive mappings and strictly pseudocontractive mappings on $\mathrm{H}$. Very recently, Buong and Phuong [5] introduced two new implicit iterative algorithms, which converge strongly in Banach spaces without weakly continuous duality mapping. These methods are two different combinations of the steepest-descent method with the V-mapping, a composition, and a convex combination.

Our purpose in this paper is to solve a general system of variational inequalities with the hierarchical variational inequality constraint for an infinite family of nonexpansive mappings in a uniformly convex and 2-uniformly smooth Banach space. By utilizing the equivalence between the GSVI (1.1) and the fixed point problem as mentioned above, we construct two new implicit iteration methods. Finally, under very 
mild conditions, we prove the strong convergence of the proposed methods by using V-mappings instead of $\mathrm{W}$-ones. Our results improve and extend the corresponding results announced by some others, e.g., Ceng et al. [7] and Buong and Phuong [5].

\section{Preliminaries}

Let $X$ be a real Banach space and $C$ be a nonempty closed convex subset of $X$. We write $x_{n} \rightarrow x$ (respectively, $x_{n} \rightarrow x$ ) to indicate that the sequence $\left\{x_{n}\right\}$ converges weakly (respectively, strongly) to $x$. A mapping $\mathrm{J}: \mathrm{X} \rightarrow 2^{\mathrm{X}^{*}}$, satisfying the condition

$$
J(x)=\left\{\varphi \in X^{*}:\langle x, \varphi\rangle=\|\varphi\|^{2} \text { and }\|\varphi\|=\|x\|\right\},
$$

is called the normalized duality mapping of $X$. We know that $J(t x)=t J(x)$ for all $t>0$ and $x \in X$, and $\mathrm{J}(-\mathrm{x})=-\mathrm{J}(\mathrm{x})$.

Let $U:=\{x \in X:\|x\|=1\}$. A Banach space $X$ is said to be uniformly convex if for each $\varepsilon \in(0,2]$, there exists $\delta>0$ such that for any $x, y \in U,\left\|\frac{x+y}{2}\right\|>1-\delta$ implies $\|x-y\|<\varepsilon$. It is known that a uniformly convex Banach space is reflexive and strictly convex. Also, it is known that if a Banach space $X$ is reflexive, then $X$ is strictly convex if and only if $X^{*}$ is smooth as well as $X$ is smooth if and only if $X^{*}$ is strictly convex.

Proposition 2.1 ([14]). Let $\mathrm{X}$ be a smooth and uniformly convex Banach space, and let $\mathrm{r}>0$. Then there exists a strictly increasing, continuous, and convex function $\mathrm{g}:[0,2 \mathrm{r}] \rightarrow \mathbf{R}, \mathrm{g}(0)=0$ such that

$$
g(\|x-y\|) \leqslant\|x\|^{2}-2\langle x, j(y)\rangle+\|y\|^{2}, \quad \forall x, y \in B_{r},
$$

where $B_{r}=\{x \in X:\|x\| \leqslant r\}$.

Here we define a function $\rho:[0, \infty) \rightarrow[0, \infty)$ called the modulus of smoothness of $X$ as follows:

$$
\rho(\tau)=\sup \left\{\frac{1}{2}(\|x+y\|+\|x-y\|)-1: x, y \in X,\|x\|=1,\|y\|=\tau\right\} .
$$

It is known that $X$ is uniformly smooth if and only if $\lim _{\tau \rightarrow 0^{+}} \rho(\tau) / \tau=0$. Let $q$ be a fixed real number with $1<q \leqslant 2$. Then a Banach space $X$ is said to be $q$-uniformly smooth if there exists a constant $c>0$ such that $\rho(\tau) \leqslant c \tau^{q}$ for all $\tau>0$. Takahashi et al. [21] reminded us of the fact that no Banach space is q-uniformly smooth for $\mathrm{q}>2$. In this paper, we focus on only a 2-uniformly smooth Banach space.

Lemma 2.2 ([23]). Let $\mathrm{q}$ be a given real number with $1<\mathrm{q} \leqslant 2$ and let $\mathrm{X}$ be a $\mathrm{q}$-uniformly smooth Banach space. Then

$$
\|x+y\|^{q} \leqslant\|x\|^{q}+q\left\langle y, J_{q}(x)\right\rangle+2\|k y\|^{q}, \quad \forall x, y \in X,
$$

where $\mathrm{K}$ is the $\mathrm{q}$-uniformly smooth constant of $\mathrm{X}$ and $\mathrm{J}_{\mathrm{q}}$ is the generalized duality mapping from $\mathrm{X}$ into $2^{\mathrm{X}^{*}}$ defined by

$$
\mathrm{J}_{\mathbf{q}}(x)=\left\{\varphi \in X^{*}:\langle\varphi, x\rangle=\|x\|^{\mathbf{q}},\|\varphi\|=\|x\|^{\mathbf{q}-1}\right\}, \quad \forall x \in X .
$$

Let $D$ be a subset of $C$ and let $\Pi$ be a mapping of $C$ into $D$. Then $\Pi$ is said to be sunny if

$$
\Pi[\Pi(\mathrm{x})+\mathrm{t}(\mathrm{x}-\Pi(\mathrm{x}))]=\Pi(\mathrm{x}),
$$

whenever $\Pi(x)+t(x-\Pi(x)) \in C$ for $x \in C$ and $t \geqslant 0$. A mapping $\Pi$ of $C$ into itself is called a retraction if $\Pi^{2}=\Pi$. If a mapping $\Pi$ of $C$ into itself is a retraction, then $\Pi(z)=z$ for each $z \in R(\Pi)$, where $R(\Pi)$ is the range of $\Pi$. A subset $D$ of $C$ is called a sunny nonexpansive retract of $C$ if there exists a sunny nonexpansive retraction from $\mathrm{C}$ onto $\mathrm{D}$.

Lemma $2.3([18,26])$. Let $\mathrm{C}$ be a nonempty closed convex subset of a smooth Banach space $\mathrm{X}$ and $\mathrm{D}$ be a nonempty subset of $\mathrm{C}$ and $\Pi$ be a retraction of $\mathrm{C}$ onto $\mathrm{D}$. Then the followings are equivalent: 
(i) $\Pi$ is sunny and nonexpansive;

(ii) $\|\Pi(x)-\Pi(y)\|^{2} \leqslant\langle x-y, j(\Pi(x)-\Pi(y))\rangle, \forall x, y \in C$;

(iii) $\langle x-\Pi(x), j(y-\Pi(x))\rangle \leqslant 0, \forall x \in C, y \in D$.

It is well-known that if $X$ is a Hilbert space, then a sunny nonexpansive retraction $\Pi_{C}$ coincides with the metric projection from $X$ onto $C$.

Lemma 2.4 ([27]). Let $C$ be a nonempty closed convex subset of a real 2-uniformly smooth Banach space X. Let $\Pi_{\mathrm{C}}$ be a sunny nonexpansive retraction from $\mathrm{X}$ onto $\mathrm{C}$. Let the mappings $\mathrm{A}, \mathrm{B}: \mathrm{C} \rightarrow \mathrm{X}$ be $\alpha$-inversestrongly accretive and $\beta$-inverse-strongly accretive, respectively. For given $x^{*}, y^{*} \in C,\left(x^{*}, y^{*}\right)$ is a solution of the GSVI (1.1) if and only if $x^{*} \in \operatorname{GSVI}(\mathrm{C}, \mathrm{A}, \mathrm{B})$ where $\operatorname{GSVI}(\mathrm{C}, \mathrm{A}, \mathrm{B})$ is the set of fixed points of the mapping $\mathrm{G}:=\Pi_{\mathrm{C}}(\mathrm{I}-\lambda \mathrm{A}) \Pi_{\mathrm{C}}(\mathrm{I}-\mu \mathrm{B})$ and $\mathrm{y}^{*}=\Pi_{\mathrm{C}}\left(\mathrm{x}^{*}-\mu \mathrm{B} x^{*}\right)$.

Proposition 2.5 ([28]). Let $\mathrm{C}$ be a nonempty closed convex subset of a real 2-uniformly smooth Banach space $\mathrm{X}$. Let the mapping $\mathrm{A}: \mathrm{C} \rightarrow \mathrm{X}$ be $\alpha$-inverse-strongly accretive. Then,

$$
\|(I-\lambda A) x-(I-\lambda A) y\|^{2} \leqslant\|x-y\|^{2}+2 \lambda\left(k^{2} \lambda-\alpha\right)\|A x-A y\|^{2} .
$$

In particular, if $0 \leqslant \lambda \leqslant \frac{\alpha}{\kappa^{2}}$, then $\mathrm{I}-\lambda \mathrm{A}$ is nonexpansive.

Lemma 2.6 ([27]). Let $\mathrm{C}$ be a nonempty closed convex subset of a real 2-uniformly smooth Banach space X. Let $\Pi_{\mathrm{C}}$ be a sunny nonexpansive retraction from $\mathrm{X}$ onto $\mathrm{C}$. Let the mappings $\mathrm{A}, \mathrm{B}: \mathrm{C} \rightarrow \mathrm{X}$ be $\alpha$-inversestrongly accretive and $\beta$-inverse-strongly accretive, respectively. Let the mapping $\mathrm{G}: \mathrm{C} \rightarrow \mathrm{C}$ be defined as $\mathrm{G}:=$ $\Pi_{\mathrm{C}}(\mathrm{I}-\lambda \mathrm{A}) \Pi_{\mathrm{C}}(\mathrm{I}-\mu \mathrm{B})$. If $0 \leqslant \lambda \leqslant \frac{\alpha}{\mathrm{K}^{2}}$ and $0 \leqslant \mu \leqslant \frac{\beta}{\mathrm{K}^{2}}$, then $\mathrm{G}: \mathrm{C} \rightarrow \mathrm{C}$ is nonexpansive.

Let $C$ be a nonempty closed convex subset of a uniformly convex and 2-uniformly smooth Banach space $X$. Let $\Pi_{C}$ be a sunny nonexpansive retraction from $X$ onto $C$. Let the mappings $A, B: C \rightarrow X$ be $\alpha$-inverse-strongly accretive and $\beta$-inverse-strongly accretive, respectively. Let $F: C \rightarrow X$ be $\delta$-strongly accretive and $\zeta$-strictly pseudocontractive with $\delta+\zeta>1$. Assume that $\lambda \in\left(0, \frac{\alpha}{\kappa^{2}}\right)$ and $\mu \in\left(0, \frac{\beta}{\kappa^{2}}\right)$ where $K$ is the 2-uniformly smooth constant of $X$ (see Lemma 2.3). Very recently, in order to solve GSVI (1.1), Ceng et al. [7] introduced an implicit algorithm of Mann's type.

Algorithm 2.7 ([7, Algorithm 3.6]). For each $t \in(0,1)$, choose a number $\theta_{t} \in(0,1)$ arbitrarily. Let the net $\left\{x_{\mathrm{t}}\right\}$ be generated by the implicit method

$$
x_{\mathrm{t}}=\mathrm{tG} x_{\mathrm{t}}+(1-\mathrm{t}) \Pi_{\mathrm{C}}\left(\mathrm{I}-\theta_{\mathrm{t}} \mathrm{F}\right) \mathrm{G} \mathrm{x}_{\mathrm{t}}, \quad \forall \mathrm{t} \in(0,1),
$$

where $x_{t}$ is a unique fixed point of the contraction $W_{t}=t G+(1-t) \Pi_{C}\left(I-\theta_{t} F\right) G$.

It was proven in [7] that the net $\left\{x_{t}\right\}$ converges in norm, as $t \rightarrow 0^{+}$, to the unique solution $x^{*} \in$ $\operatorname{GSVI}(C, A, B)$ of the following VI:

$$
\left\langle F\left(x^{*}\right), j\left(x-x^{*}\right)\right\rangle \geqslant 0, \quad \forall x \in \operatorname{GSVI}(C, A, B),
$$

provided $\lim _{\mathrm{t} \rightarrow 0^{+}} \theta_{\mathrm{t}}=0$.

Let $F$ be a mapping with domain $D(F)$ and range $R(F)$ in $X . F$ is called

(a) accretive if for each $x, y \in D(F)$, there exists $j(x-y) \in J(x-y)$ such that

$$
\langle F x-F y, j(x-y)\rangle \geqslant 0,
$$

where $\mathrm{J}$ is the normalized duality mapping;

(b) $\delta$-strongly accretive if for each $x, y \in D(F)$, there exists $j(x-y) \in J(x-y)$ such that

$$
\langle F x-F y, j(x-y)\rangle \geqslant \delta\|x-y\|^{2} \quad \text { for some } \delta \in(0,1) ;
$$


(c) $\alpha$-inverse-strongly accretive if for each $x, y \in D(F)$, there exists $j(x-y) \in J(x-y)$ such that

$$
\langle F x-F y, j(x-y)\rangle \geqslant \alpha\|F x-F y\|^{2} \quad \text { for some } \alpha \in(0,1) ;
$$

(d) $\zeta$-strictly pseudocontractive if for each $x, y \in D(F)$, there exists $j(x-y) \in J(x-y)$ such that

$$
\langle F x-F y, j(x-y)\rangle \leqslant\|x-y\|^{2}-\zeta\|x-y-(F x-F y)\|^{2} \text { for some } \zeta \in(0,1)
$$

It is easy to see that (2.1) can be rewritten as

$$
\langle(I-F) x-(I-F) y, j(x-y)\rangle \geqslant \zeta\|(I-F) x-(I-F) y\|^{2},
$$

where I denotes the identity mapping of X. Clearly, if $F$ satisfies $(2.1)$ with $\zeta=0$, then it is said to be pseudocontractive.

Let $\left\{T_{i}\right\}_{i=1}^{\infty}$ be an infinite family of nonexpansive self-mappings on C. Set $\mathcal{F}:=\bigcap_{i=1}^{\infty} \operatorname{Fix}\left(T_{i}\right)$. In 2013, Buong and Phuong [5] considered the following HVI with $C=X$ of finding $x^{*} \in \mathcal{F}$ such that

$$
\left\langle F\left(x^{*}\right), j\left(x-x^{*}\right)\right\rangle \geqslant 0, \quad \forall x \in \mathcal{F} .
$$

In the case of $X=H$, we have $J=I$, and hence problem (2.2) reduces to the HVI of finding $x^{*} \in \mathcal{F}$ such that

$$
\left\langle\mathrm{F}\left(\mathrm{x}^{*}\right), x-\mathrm{x}^{*}\right\rangle \geqslant 0, \quad \forall x \in \mathcal{F} .
$$

In [32], Zeng and Yao introduced the following implicit iteration. For an arbitrarily initial point $x_{0} \in H$, define the sequence $\left\{x_{k}\right\}_{k=1}^{\infty}$ by

$$
x_{k}=\beta_{k} x_{k-1}+\left(1-\beta_{k}\right)\left[T_{[k]} x_{k}-\lambda_{k} \mu F\left(T_{[k]} x_{k}\right)\right], \quad \forall k \geqslant 1,
$$

where $T_{[n]}=T_{n \bmod N}$, for integer $n \geqslant 1$, with the $\bmod$ function taking values in the set $\{1,2, \ldots, N\}$. They proved the following result.

Theorem 2.8 ([32, Theorem 2.1]). Let $\mathrm{H}$ be a real Hilbert space and let $\mathrm{F}: \mathrm{H} \rightarrow \mathrm{H}$ be an L-Lipschitz and $\eta$-strongly monotone mapping. Let $\left\{\mathrm{T}_{i}\right\}_{i=1}^{\mathrm{N}}$ be $\mathrm{N}$ nonexpansive mappings on $\mathrm{H}$ such that $\mathcal{F} \neq \emptyset$. Let $\mu \in\left(0,2 \eta / \mathrm{L}^{2}\right),\left\{\lambda_{\mathrm{k}}\right\}_{\mathrm{k}=1}^{\infty} \subset$ $[0,1)$ and $\left\{\beta_{k}\right\}_{k=1}^{\infty} \subset(0,1)$ satisfying the conditions $\sum_{k=1}^{\infty} \lambda_{k}<\infty$ and $0<a \leqslant \beta_{k} \leqslant b<1$ for all $k \geqslant 1$. Then the sequence $\left\{x_{\mathrm{k}}\right\}_{\mathrm{k}=0}^{\infty}$ defined by (2.4) converges weakly to $x^{*} \in \mathcal{F}$ which solves (2.3).

Recently, in order to obtain the strong convergence, Buong and Anh [4] proposed the following implicit iteration method:

$$
x_{t}=T^{t} x_{t}, \quad T^{t}:=T_{0}^{t} T_{N}^{t} \cdot T_{1}^{t}, t \in(0,1),
$$

where $\left\{T_{i}^{t}\right\}_{i=0}^{N}$ are defined by

$$
T_{i}^{t} x:=\left(1-\beta_{t}^{i}\right) x+\beta_{t}^{i} T_{i} x, \quad i=1, \ldots, N, \quad T_{0}^{t} y:=\left(I-\lambda_{t} \mu F\right) y, \quad x, y \in H,
$$

and proved that the net $\left\{x_{t}\right\}$ defined by (2.5) and (2.6) converges strongly to an element $x^{*}$. When $N=1, X$ is a real reflexive and strictly convex Banach space with a uniformly Gâteaux differentiable norm and $\mathrm{T}$ is a continuous pseudocontractive mapping, Ceng et al. [6] proved the following result.

Theorem 2.9 ([6, Proposition 4.3]). Let $\mathrm{F}$ be a $\delta$-strongly accretive and $\zeta$-strictly pseudocontractive mapping with $\delta+\zeta>1$ and let $\mathrm{T}$ be a continuous and pseudocontractive mapping on $\mathrm{X}$, which is a real reflexive and strictly convex Banach space with a uniformly Gâteaux differentiable norm, such that $\mathcal{F} \neq \emptyset$. For each $\mathrm{t} \in(0,1)$, choose a number $\mu_{\mathrm{t}} \in(0,1)$ arbitrarily and let $\left\{z_{\mathrm{t}}\right\}$ be defined by

$$
z_{\mathrm{t}}=\mathrm{t}\left(\mathrm{I}-\mu_{\mathrm{t}} \mathrm{F}\right) z_{\mathrm{t}}+(1-\mathrm{t}) \mathrm{T} z_{\mathrm{t}} .
$$

Then, as $\mathrm{t} \rightarrow 0^{+},\left\{z_{\mathrm{t}}\right\}$ converges strongly to $\mathrm{x}^{*} \in \mathcal{F}$ which solves (2.2). 
To find a common fixed point of an infinite family $\left\{\mathrm{T}_{i}\right\}_{i=1}^{\infty}$ of nonexpansive mappings on a nonempty, closed, and convex subset $C$ in $H$, Takahashi [20] introduced a $W$-mapping, generated by $T_{k}, T_{k-1}, \cdots, T_{1}$ and real numbers $\alpha_{k}, \alpha_{k-1}, \cdots, \alpha_{1}$ as follows:

$$
\left\{\begin{array}{l}
\mathrm{U}_{k, k+1}=\mathrm{I}, \\
\mathrm{U}_{k, k}=\alpha_{k} \mathrm{~T}_{k} \mathrm{U}_{k, k+1}+\left(1-\alpha_{\mathrm{k}}\right) \mathrm{I} \\
\mathrm{U}_{k, k-1}=\alpha_{k-1} \mathrm{~T}_{k-1} \mathrm{U}_{k, k}+\left(1-\alpha_{k-1}\right) \mathrm{I} \\
\vdots \\
\mathrm{U}_{k, 2}=\alpha_{2} \mathrm{~T}_{2} \mathrm{U}_{k, 3}+\left(1-\alpha_{2}\right) \mathrm{I} \\
W_{k}=\mathrm{U}_{k, 1}=\alpha_{1} \mathrm{~T}_{1} \mathrm{U}_{\mathrm{k}, 2}+\left(1-\alpha_{1}\right) \mathrm{I}
\end{array}\right.
$$

By using W-mapping, in [15], Kikkawa and Takahashi introduced the following implicit algorithm:

$$
\mathrm{S}_{\mathrm{k}} \mathrm{x}=\left(1-\frac{1}{\mathrm{k}}\right) \mathrm{U} \mathrm{x}+\frac{1}{\mathrm{k}} \mathrm{f}(\mathrm{x}), \text { and } \mathrm{U} x=\lim _{\mathrm{k} \rightarrow \infty} \mathrm{W}_{\mathrm{k}} \mathrm{x}=\lim _{\mathrm{k} \rightarrow \infty} \mathrm{U}_{\mathrm{k}, 1} x .
$$

Note that the method (2.8) contains the limit mapping $U$, and hence, it is difficult to implement.

In [5], motivated by methods (2.5) and (2.7), Buong and Phuong introduced a mapping $V_{k}$, defined by

$$
V_{k}=V_{k}^{1}, \quad V_{k}^{i}=T^{i} T^{i+1} \ldots T^{k}, \quad T^{i}=\left(1-\alpha_{i}\right) I+\alpha_{i} T_{i}, i=1,2, \ldots, k,
$$

where

$$
\alpha_{i} \in(0,1) \text { and } \sum_{i=1}^{\infty} \alpha_{i}<\infty .
$$

Buong and Phuong considered the following implicit methods:

$$
x_{k}=V_{k}\left(I-\lambda_{k} F\right) x_{k}, \quad \forall k \geqslant 1,
$$

and

$$
x_{k}=\gamma_{k}\left(I-\lambda_{k} F\right) x_{k}+\left(I-\gamma_{k}\right) V_{k} x_{k}, \quad \forall k \geqslant 1,
$$

where $\lambda_{k}$ and $\gamma_{k}$ are the positive parameters.

We will make use of the following well-known results in the next section.

Lemma 2.10. Let $\mathrm{X}$ be a real normed linear space. Then, the following inequality holds:

$$
\|x+y\|^{2} \leqslant\|x\|^{2}+2\langle y, j(x+y)\rangle, \quad \forall x, y \in X, \forall j(x+y) \in J(x+y) .
$$

Lemma 2.11 ([3]). Let $\mathrm{C}$ be a nonempty closed convex subset of a uniformly convex Banach space $\mathrm{X}$ and $\mathrm{T}: \mathrm{C} \rightarrow \mathrm{C}$ be a nonexpansive mapping with $\operatorname{Fix}(T) \neq \emptyset$. If $\left\{x_{n}\right\}$ is a sequence of $C$ such that $x_{n} \rightarrow x$ and $(I-T) x_{n} \rightarrow y$, then $(\mathrm{I}-\mathrm{T}) \mathrm{x}=\mathrm{y}$. In particular, if $\mathrm{y}=0$, then $\mathrm{x} \in \operatorname{Fix}(\mathrm{T})$.

Lemma 2.12 ([27]). Let $\mathrm{C}$ be a nonempty closed convex subset of a real smooth Banach space $\mathrm{X}$. Assume that the mapping $\mathrm{F}: \mathrm{C} \rightarrow \mathrm{X}$ is accretive and weakly continuous along segments (that is, $\mathrm{F}(\mathrm{x}+\mathrm{ty}) \rightarrow \mathrm{F}(\mathrm{x})$ as $\mathrm{t} \rightarrow 0$ ). Then the variational inequality

$$
x^{*} \in \mathrm{C}, \quad\left\langle\mathrm{F}\left(x^{*}\right), j\left(x-x^{*}\right)\right\rangle \geqslant 0, \quad \forall x \in \mathrm{C}
$$

is equivalent to the following Minty type variational inequality:

$$
x^{*} \in \mathrm{C}, \quad\left\langle\mathrm{F}(\mathrm{x}), \mathrm{j}\left(\mathrm{x}-\mathrm{x}^{*}\right)\right\rangle \geqslant 0, \quad \forall x \in \mathrm{C} .
$$

Lemma 2.13 ([7]). Let $\mathrm{X}$ be a real smooth Banach space and $\mathrm{F}: \mathrm{C} \rightarrow \mathrm{X}$ be a mapping.

(a) If $\mathrm{F}$ is $\zeta$-strictly pseudocontractive, then $\mathrm{F}$ is Lipschitz continuous with constant $1+\frac{1}{\zeta}$.

(b) If $\mathrm{F}$ is $\delta$-strongly accretive and $\zeta$-strictly pseudocontractive with $\delta+\zeta>1$, then $\mathrm{I}-\mathrm{F}$ is contractive with constant $\sqrt{\frac{1-\delta}{\zeta}} \in(0,1)$.

(c) If $\mathrm{F}$ is $\delta$-strongly accretive and $\zeta$-strictly pseudocontractive with $\delta+\zeta>1$, then for any fixed number $\lambda \in(0,1), \mathrm{I}-\lambda \mathrm{F}$ is contractive with constant $1-\lambda\left(1-\sqrt{\frac{1-\delta}{\zeta}}\right) \in(0,1)$. 


\section{Main results}

In this section, we study the iterative methods for computing the approximate solutions of the GSVI (1.1) with the HVI constraint for an infinite family of nonexpansive mappings. We introduce two implicit iterative algorithms for solving such a problem. We show the strong convergence of the sequences generated by the proposed algorithms.

The following lemmas and proposition will be used to prove our main results in the sequel.

Lemma 3.1. Let $\mathrm{C}$ be a nonempty closed convex subset of a strictly convex and 2-uniformly smooth Banach space $\mathrm{X}$. Let $\Pi_{\mathrm{C}}$ be a sunny nonexpansive retraction from $\mathrm{X}$ onto $\mathrm{C}$. Let the mappings $\mathrm{A}, \mathrm{B}: \mathrm{C} \rightarrow \mathrm{X}$ be $\alpha$-inversestrongly accretive and $\beta$-inverse-strongly accretive, respectively. Let the mapping $\mathrm{G}: \mathrm{C} \rightarrow \mathrm{C}$ be defined as $\mathrm{G}:=$ $\Pi_{\mathrm{C}}(\mathrm{I}-\lambda \mathrm{A}) \Pi_{\mathrm{C}}(\mathrm{I}-\mu \mathrm{B})$, where $0<\lambda \leqslant \frac{\alpha}{\kappa^{2}}$ and $0<\mu \leqslant \frac{\beta}{\kappa^{2}}$. Let $\left\{\mathrm{T}_{i}\right\}_{i=1}^{k}$ be $\mathrm{k}$ nonexpansive self-mappings on $\mathrm{C}$ such that $\mathcal{F}:=\bigcap_{i=1}^{k} \operatorname{Fix}\left(\mathrm{T}_{i}\right) \cap \operatorname{GSVI}(\mathrm{C}, \mathrm{A}, \mathrm{B}) \neq \emptyset$. Let $\mathrm{a}, \mathrm{b}$ and $\alpha_{i}(\mathfrak{i}=1,2, \cdots, \mathrm{k})$ be real numbers such that $0<\mathrm{a} \leqslant \alpha_{\mathrm{i}} \leqslant \mathrm{b}<1$, and let $\mathrm{V}_{\mathrm{k}}$ be a mapping defined by (2.9) for all $\mathrm{k} \geqslant 1$. Then, $\operatorname{Fix}\left(\mathrm{V}_{\mathrm{k}} \circ \mathrm{G}\right)=\mathcal{F}$.

Proof. First of all, according to Lemma 2.6 we know that $\mathrm{G}: \mathrm{C} \rightarrow \mathrm{C}$ is a nonexpansive mapping for $0<\lambda \leqslant \frac{\alpha}{k^{2}}$ and $0<\mu \leqslant \frac{\beta}{\kappa^{2}}$. Note that when $k=1$ we have $\operatorname{Fix}\left(V_{1}\right)=\operatorname{Fix}\left(T^{1}\right)=\operatorname{Fix}\left(T_{1}\right)$. We claim that $\operatorname{Fix}\left(V_{1} \circ G\right) \subset \mathcal{F}$. Indeed, observe that for each $z \in \operatorname{Fix}\left(V_{1} \circ G\right)$ and $p \in \mathcal{F}=\operatorname{Fix}\left(T_{1}\right) \cap \operatorname{GSVI}(C, A, B)$,

$$
\|z-p\|=\left\|T^{1} G z-T^{1} p\right\| \leqslant\|G z-p\|=\|G z-G p\| \leqslant\|z-p\|,
$$

which immediately yields

$$
\|G z-p\|=\left\|\left[\left(1-\alpha_{1}\right) I+\alpha_{1} T_{1}\right] G z-p\right\|=\left\|\left(1-\alpha_{1}\right)(G z-p)+\alpha_{1}\left(T_{1} G z-p\right)\right\| .
$$

Since $X$ is strictly convex and $\alpha_{1} \in[a, b]$ with $a, b \in(0,1)$, we obtain $T_{1} G z-p=G z-p$, and hence $\mathrm{T}_{1} \mathrm{Gz}=\mathrm{G} z$. So, we get

$$
z=\mathrm{T}^{1} \mathrm{G} z=\left[\left(1-\alpha_{1}\right) \mathrm{I}+\alpha_{1} \mathrm{~T}_{1}\right] \mathrm{G} z=\left(1-\alpha_{1}\right) \mathrm{G} z+\alpha_{1} \mathrm{~T}_{1} \mathrm{G} z=\left(1-\alpha_{1}\right) \mathrm{G} z+\alpha_{1} \mathrm{G} z=\mathrm{G} z,
$$

which together with $T_{1} G z=G z$, implies that $T_{1} z=z$. Thus, $z \in \operatorname{Fix}\left(T_{1}\right) \cap \operatorname{GSVI}(C, A, B)=\mathcal{F}$. In addition, for each $p \in \mathcal{F}$, we have

$$
\left(V_{1} \circ G\right) p=\left[\left(1-\alpha_{1}\right) I+\alpha_{1} T_{1}\right] G p=\left[\left(1-\alpha_{1}\right) I+\alpha_{1} T_{1}\right] p=p,
$$

which implies $p \in \operatorname{Fix}\left(V_{1} \circ G\right)$. So, we get $\mathcal{F} \subset \operatorname{Fix}\left(V_{1} \circ G\right)$. Consequently, $\operatorname{Fix}\left(V_{1} \circ G\right)=\mathcal{F}$.

Next we shall give a proof for the case when $k>1$. First, we show that $\mathcal{F} \subset \operatorname{Fix}\left(V_{k} \circ G\right)$. Indeed, for each $p \in \mathcal{F}$, we have

$$
T^{i} p=\left[\left(1-\alpha_{i}\right) I+\alpha_{i} T_{i}\right] p=p, \quad \forall i=1,2, \cdots, k .
$$

Hence, $V_{k} p=T^{1} T^{2} \ldots T^{k} p=p$. Consequently, $\left(V_{k} \circ G\right) p=V_{k} p=p$. Now, we shall prove that $\operatorname{Fix}\left(V_{k} \circ\right.$ $\mathrm{G}) \subset \mathcal{F}$. Take any $z \in \operatorname{Fix}\left(V_{k} \circ G\right)$ and $p \in \mathcal{F}$. It follows from (3.1) that

$$
\begin{aligned}
\|z-p\| & =\left\|T^{1} T^{2} \cdots T^{k} G z-p\right\| \\
& =\left\|T^{1} T^{2} \cdots T^{k} G z-T^{1} p\right\| \\
& \leqslant\left\|T^{2} \cdots T^{k} G z-p\right\| \\
& =\left\|T^{2} \cdots T^{k} G z-T^{2} p\right\| \\
& \leqslant \cdots \\
& \leqslant\left\|T^{k-1} T^{k} G z-p\right\| \\
& =\left\|T^{k-1} T^{k} G z-T^{k-1} p\right\| \\
& \leqslant\left\|T^{k} G z-p\right\| \\
& =\left\|T^{k} G z-T^{k} p\right\| \\
& \leqslant\|G z-p\| \\
& =\|G z-G p\| \\
& \leqslant\|z-p\| .
\end{aligned}
$$


Therefore,

$$
\|G z-p\|=\left\|\left[\left(1-\alpha_{k}\right) I+\alpha_{k} T_{k}\right] G z-p\right\|=\left\|\left(1-\alpha_{k}\right)(G z-p)+\alpha_{k}\left(T_{k} G z-p\right)\right\| .
$$

Since $X$ is strictly convex and $\alpha_{k} \in[a, b]$ with $a, b \in(0,1)$, we obtain $T_{k} G z-p=G z-p$, and hence $T_{k} G z=G z$. So, $G z \in \operatorname{Fix}\left(T_{k}\right)$ for each $z \in \operatorname{Fix}\left(V_{k} \circ G\right)$. Moreover,

$$
\left\|\left[\left(1-\alpha_{k-1}\right) I+\alpha_{k-1} T_{k-1}\right] T^{k} G z-p\right\|=\left\|\left[\left(1-\alpha_{k-1}\right) I+\alpha_{k-1} T_{k-1}\right] G z-p\right\| .
$$

Now, from (3.2) it follows that

$$
\|\mathrm{G} z-\mathrm{p}\|=\left\|\left[\left(1-\alpha_{k-1}\right) \mathrm{I}+\alpha_{\mathrm{k}-1} \mathrm{~T}_{\mathrm{k}-1}\right] \mathrm{G} z-\mathrm{p}\right\|=\left\|\left(1-\alpha_{\mathrm{k}-1}\right)(\mathrm{G} z-\mathrm{p})+\alpha_{\mathrm{k}-1}\left(\mathrm{~T}_{\mathrm{k}-1} \mathrm{G} z-\mathrm{p}\right)\right\| .
$$

Again, since $X$ is strictly convex and $\alpha_{k-1} \in[a, b]$ with $a, b \in(0,1)$, we have $T_{k-1} G z-p=G z-p$, and hence, $T_{k-1} G z=G z$. So, $G z \in \operatorname{Fix}\left(T_{k-1}\right)$. Similarly, we obtain $G z \in \operatorname{Fix}\left(T_{i}\right)$ for all $i=1,2, \cdots, k$. Thus, we have

$$
\begin{aligned}
z & =\mathrm{T}^{1} \cdots \mathrm{T}^{\mathrm{k}-1} \mathrm{~T}^{\mathrm{k}} \mathrm{Gz} \\
& =\mathrm{T}^{1} \cdots \mathrm{T}^{\mathrm{k}-1}\left[\left(1-\alpha_{\mathrm{k}}\right) \mathrm{G} z+\alpha_{\mathrm{k}} \mathrm{T}_{\mathrm{k}} \mathrm{G} z\right] \\
& =\mathrm{T}^{1} \cdots \mathrm{T}^{\mathrm{k}-1}\left[\left(1-\alpha_{\mathrm{k}}\right) \mathrm{G} z+\alpha_{\mathrm{k}} \mathrm{G} z\right] \\
& =\mathrm{T}^{1} \cdots \mathrm{T}^{\mathrm{k}-1} \mathrm{Gz} \\
& =\mathrm{T}^{1} \cdots \mathrm{T}^{\mathrm{k}-2} \mathrm{~T}^{\mathrm{k}-1} \mathrm{G} z \\
& =\mathrm{T}^{1} \cdots \mathrm{T}^{\mathrm{k}-2} \mathrm{Gz} \\
& \vdots \\
& =\mathrm{G} z,
\end{aligned}
$$

which together with $T_{i} G z=G z$ implies that $T_{i} z=z$ for all $i=1,2, \cdots, k$. Therefore, $z \in \bigcap_{i=1}^{k} \operatorname{Fix}\left(T_{i}\right) \cap$ $\operatorname{GSVI}(C, A, B)=\mathcal{F}$. It means that $\operatorname{Fix}\left(V_{k} \circ G\right) \subset \mathcal{F}$. This completes the proof.

Proposition 3.2 ([5, Lemma 3.2]). Let $\mathrm{C}$ be a nonempty closed convex subset of a Banach space $\mathrm{X}$ and let $\left\{\mathrm{T}_{i}\right\}_{i=1}^{\infty}$ be an infinite family of nonexpansive self-mappings on $\mathrm{C}$ such that the set of common fixed points $\mathcal{F}:=\bigcap_{i=1}^{\infty} \operatorname{Fix}\left(\mathrm{T}_{i}\right) \neq$ $\emptyset$. Let $V_{k}$ be a mapping defined by (2.9), and let $\alpha_{i}$ satisfy (2.10). Then, for each $x \in C$ and $i \geqslant 1, \lim _{k \rightarrow \infty} V_{k}^{i} x$ exists.

Now, we can define the mappings

$$
V_{\infty}^{i} x:=\lim _{k \rightarrow \infty} V_{k}^{i} x \text { and } V x:=\lim _{k \rightarrow \infty} V_{k} x
$$

Lemma 3.3. Let $\mathrm{C}$ be a nonempty closed convex subset of a 2-uniformly smooth Banach space $\mathrm{X}$. Let $\Pi_{\mathrm{C}}$ be a sunny nonexpansive retraction from $\mathrm{X}$ onto $\mathrm{C}$. Let the mappings $\mathrm{A}, \mathrm{B}: \mathrm{C} \rightarrow \mathrm{X}$ be $\alpha$-inverse-strongly accretive and $\beta$-inverse-strongly accretive, respectively. Let the mapping $\mathrm{G}: \mathrm{C} \rightarrow \mathrm{C}$ be defined as $\mathrm{G}:=\Pi_{\mathrm{C}}(\mathrm{I}-\lambda \mathrm{A}) \Pi_{\mathrm{C}}(\mathrm{I}-\mu \mathrm{B})$, where $0<\lambda \leqslant \frac{\alpha}{\kappa^{2}}$ and $0<\mu \leqslant \frac{\beta}{\kappa^{2}}$. Let $\left\{\mathrm{T}_{i}\right\}_{i=1}^{\infty}$ be an infinite family of nonexpansive self-mappings on $\mathrm{C}$ such that $\mathcal{F}:=\bigcap_{i=1}^{\infty} \operatorname{Fix}\left(T_{i}\right) \cap \operatorname{GSVI}(C, A, B) \neq \emptyset$. Let $V_{k}$ be a mapping defined by (2.9) and let $\alpha_{i}$ satisfy (2.10). Then, for each $\mathrm{x} \in \mathrm{C}$ and $\mathrm{i} \geqslant 1, \lim _{\mathrm{k} \rightarrow \infty} \mathrm{V}_{\mathrm{k}}^{\mathrm{i}} \mathrm{G} x$ exists.

Proof. Let $p \in \mathcal{F}$ and $x \in C$ such that $p \neq x$. Then, for $k \geqslant 1$ with fixed $k \geqslant i$, we have

$$
\begin{aligned}
\left\|V_{k+1}^{i} G x-V_{k}^{i} G x\right\| & =\left\|T^{i} T^{i+1} \cdots T^{k} T^{k+1} G x-T^{i} T^{i+1} \ldots T^{k} G x\right\| \\
& \leqslant\left\|T^{k+1} G x-G x\right\| \\
& =\left\|\left(1-\alpha_{k+1}\right) G x+\alpha_{k+1} T_{k+1} G x-G x\right\| \\
& =\alpha_{k+1}\left\|T_{k+1} G x-T_{k+1} G p+G p-G x\right\| \\
& \leqslant 2 \alpha_{k+1}\|x-p\| .
\end{aligned}
$$


By virtue of (2.10), we have $\lim _{n, m \rightarrow \infty} \sum_{j=n}^{m} \alpha_{j}=0$. So, for any $\varepsilon>0$, there exists an integer $k_{0} \geqslant 1$ with $k_{0} \geqslant i$ such that, for any $n, m$ with $m>n>k_{0}$, we have

$$
\sum_{j=n}^{m-1} \alpha_{j+1}<\frac{\varepsilon}{2\|x-p\|}
$$

Therefore,

$$
\left\|V_{m}^{i} G x-V_{n}^{i} G x\right\| \leqslant \sum_{j=n}^{m-1}\left\|V_{j+1}^{i} G x-V_{j}^{i} G x\right\| \leqslant \sum_{j=n}^{m-1}\left(2 \alpha_{j+1}\|x-p\|\right)=2\|x-p\| \sum_{j=n}^{m-1} \alpha_{j+1}<\varepsilon .
$$

This implies that $\left\{V_{k}^{i} G x\right\}$, for each fixed $i$, is a Cauchy sequence in the Banach space $X$ and hence $\lim _{k \rightarrow \infty} V_{k}^{i} G x$ exists.

Here, we can derive the followings

$$
\mathrm{V}_{\infty}^{\mathrm{i}} \mathrm{Gx}:=\lim _{\mathrm{k} \rightarrow \infty} \mathrm{V}_{\mathrm{k}}^{\mathrm{i}} \mathrm{G} x \text { and }(\mathrm{V} \circ \mathrm{G}) \mathrm{x}:=\lim _{\mathrm{k} \rightarrow \infty} \mathrm{V}_{\mathrm{k}} \mathrm{G} x
$$

Lemma 3.4. Let $\mathrm{C}$ be a nonempty closed convex subset of a strictly convex and 2-uniformly smooth Banach space $\mathrm{X}$. Let $\Pi_{\mathrm{C}}$ be a sunny nonexpansive retraction from $\mathrm{X}$ onto $\mathrm{C}$. Let the mappings $\mathrm{A}, \mathrm{B}: \mathrm{C} \rightarrow \mathrm{X}$ be $\alpha$-inversestrongly accretive and $\beta$-inverse-strongly accretive, respectively. Let the mapping $\mathrm{G}: \mathrm{C} \rightarrow \mathrm{C}$ be defined as $\mathrm{G}:=$ $\Pi_{\mathrm{C}}(\mathrm{I}-\lambda \mathrm{A}) \Pi_{\mathrm{C}}(\mathrm{I}-\mu \mathrm{B})$, where $0<\lambda \leqslant \frac{\alpha}{\mathrm{K}^{2}}$ and $0<\mu \leqslant \frac{\beta}{\mathrm{K}^{2}}$. Let $\left\{\mathrm{T}_{i}\right\}_{i=1}^{\infty}$ be an infinite family of nonexpansive self-mappings on $\mathrm{C}$ such that $\mathcal{F}:=\bigcap_{i=1}^{\infty} \operatorname{Fix}\left(\mathrm{T}_{i}\right) \cap \operatorname{GSVI}(\mathrm{C}, \mathrm{A}, \mathrm{B}) \neq \emptyset$. Let $\alpha_{i}$ satisfy the first condition in (2.10). Then, $\operatorname{Fix}(\mathrm{V} \circ \mathrm{G})=\mathcal{F}$.

Proof. Let $p \in \mathcal{F}$. Then it is obvious that $G p=p$ and $V_{k}^{i} p=p$ for all integers $i, k \geqslant 1$ with $k \geqslant i$. So, we have $V_{\infty}^{i} G p=p$ for all integers $i \geqslant 1$. In particular, we have $(V \circ G) p=V_{\infty}^{1} G p$ and hence $\mathcal{F} \subset \operatorname{Fix}(V \circ G)$. Next, we prove that $\operatorname{Fix}(V \circ G) \subset \mathcal{F}$. Now, let $x \in \operatorname{Fix}(V \circ G)$ and $y \in \mathcal{F}$. Then,

$$
\begin{aligned}
\left\|V_{k} G x-V_{k} G y\right\| & =\left\|V_{k}^{1} G x-V_{k}^{1} G y\right\| \\
& =\left\|\left(1-\alpha_{1}\right)\left(V_{k}^{2} G x-V_{k}^{2} G y\right)+\alpha_{1}\left(T_{1} V_{k}^{2} G x-T_{1} V_{k}^{2} G y\right)\right\| \\
& \leqslant\left(1-\alpha_{1}\right)\left\|V_{k}^{2} G x-V_{k}^{2} G y\right\|+\alpha_{1}\left\|V_{k}^{2} G x-V_{k}^{2} G y\right\| \\
& =\left\|V_{k}^{2} G x-V_{k}^{2} G y\right\| \\
& \leqslant\left\|V_{k}^{i+1} G x-V_{k}^{i+1} G y\right\| \\
& \leqslant\left\|V_{k}^{k} G x-V_{k}^{k} G y\right\| \\
& \leqslant\|G x-G y\| \\
& \leqslant\|x-y\|
\end{aligned}
$$

which together with $\|(V \circ G) x-(V \circ G) y\|=\|x-y\|$ implies that

$$
\left\|V_{\infty}^{i} G x-V_{\infty}^{i} G y\right\|=\left\|V_{\infty}^{i+1} G x-V_{\infty}^{i+1} G y\right\|=\|G x-y\| .
$$

Therefore, we have

$$
\left\|\left(1-\alpha_{i}\right)\left(V_{\infty}^{i+1} G x-V_{\infty}^{i+1} G y\right)+\alpha_{i}\left(T_{i} V_{\infty}^{i+1} G x-T_{i} V_{\infty}^{i+1} G y\right)\right\|=\left\|V_{\infty}^{i+1} G x-V_{\infty}^{i+1} G y\right\|=\|G x-y\|
$$

for every $i \geqslant 1$. Since $X$ is strictly convex, $0<\alpha_{i}<1$, and $y \in \mathcal{F}$, we have $G x-y=T_{i} V_{\infty}^{i+1} G x-$ $\mathrm{T}_{i} \mathrm{~V}_{\infty}^{\mathrm{i}+1} \mathrm{G} y=\mathrm{T}_{i} \mathrm{~V}_{\infty}^{\mathrm{i}+1} \mathrm{G} x-\mathrm{y}$ and $\mathrm{G} x-\mathrm{y}=\mathrm{V}_{\infty}^{\mathrm{i}+1} \mathrm{G} x-\mathrm{V}_{\infty}^{\mathrm{i}+1} \mathrm{G} y=\mathrm{V}_{\infty}^{\mathrm{i}+1} \mathrm{G} x-\mathrm{y}$, and hance, $\mathrm{Gx}=\mathrm{T}_{i} \mathrm{~V}_{\infty}^{\mathrm{i}+1} \mathrm{Gx}$ and $G x=V_{\infty}^{i+1} G x$ for every $i \geqslant 1$. Consequently, for every $i \geqslant 1$, we have $G x=T_{i} G x$. In particular, when $i=1$, we have that $G x=T_{1} V_{\infty}^{2} G x$ and $G x=V_{\infty}^{2} G x$. So, it follows that

$$
x=(V \circ G) x=\left(1-\alpha_{1}\right) V_{\infty}^{2} G x+\alpha_{1} T_{1} V_{\infty}^{2} G x=G x,
$$

which together with $G x=T_{i} G x$, for all $i \geqslant 1$, implies that for every $i \geqslant 1$, we have $x=T_{i} x$. It means that $x \in \mathcal{F}$. 
Now, we are in a position to prove the following main results.

Theorem 3.5. Let $\mathrm{C}$ be a nonempty closed convex subset of a uniformly convex and 2-uniformly smooth Banach space $\mathrm{X}$. Let $\Pi_{\mathrm{C}}$ be a sunny nonexpansive retraction from $\mathrm{X}$ onto $\mathrm{C}$. Let the mappings $\mathrm{A}, \mathrm{B}: \mathrm{C} \rightarrow \mathrm{X}$ be $\alpha$ inverse-strongly accretive and $\beta$-inverse-strongly accretive, respectively. Let $\mathrm{F}: \mathrm{C} \rightarrow \mathrm{X}$ be $\delta$-strongly accretive and $\zeta$-strictly pseudocontractive with $\delta+\zeta>1$. Assume that $\lambda \in\left(0, \frac{\alpha}{\mathrm{K}^{2}}\right)$ and $\mu \in\left(0, \frac{\beta}{\mathrm{K}^{2}}\right)$ where $\mathrm{K}$ is the 2uniformly smooth constant of $\mathrm{X}$. Let $\left\{\mathrm{T}_{i}\right\}_{i=1}^{\infty}$ be an infinite family of nonexpansive self-mappings on $\mathrm{C}$ such that $\mathcal{F}:=\bigcap_{i=1}^{\infty} \operatorname{Fix}\left(\mathrm{T}_{i}\right) \cap \operatorname{GSVI}(\mathrm{C}, \mathrm{A}, \mathrm{B}) \neq \emptyset$. Let $\left\{\mathrm{V}_{\mathrm{k}}\right\}_{\mathrm{k}=1}^{\infty}$ be defined by (2.9). Let $\left\{\mathrm{x}_{\mathrm{k}}\right\}_{\mathrm{k}=1}^{\infty}$ be defined by

$$
x_{k}=\Pi_{C}\left(I-\lambda_{k} F\right) V_{k} \Pi_{C}(I-\lambda A) \Pi_{C}(I-\mu B) x_{k}, \quad \forall k \geqslant 1,
$$

where $\lambda_{k} \in(0,1]$ and $\lambda_{k} \rightarrow 0$ as $k \rightarrow \infty$. Then $\left\{x_{k}\right\}_{k=1}^{\infty}$ converges strongly to a unique solution $x^{*} \in \mathcal{F}$ to the following VI:

$$
\left\langle\mathrm{F}\left(\mathrm{x}^{*}\right), \mathrm{j}\left(\mathrm{x}-\mathrm{x}^{*}\right)\right\rangle \geqslant 0, \quad \forall x \in \mathcal{F} .
$$

Proof. Let the mapping $\mathrm{G}: \mathrm{C} \rightarrow \mathrm{C}$ be defined as $\mathrm{G}:=\Pi_{\mathrm{C}}(\mathrm{I}-\lambda \mathrm{A}) \Pi_{\mathrm{C}}(\mathrm{I}-\mu \mathrm{B})$, where $0<\lambda<\frac{\alpha}{\kappa^{2}}$ and $0<\mu<\frac{\beta}{\kappa^{2}}$. Note that the implicit iterative scheme can be rewritten as

$$
x_{k}=\Pi_{C}\left(I-\lambda_{k} F\right) V_{k} G x_{k}, \quad \forall k \geqslant 1 .
$$

Consider the mapping $U_{k} x=\Pi_{C}\left(I-\lambda_{k} F\right) V_{k} G x$, for all $x \in C$. From Lemma 2.13 (c), it follows that for each $x, y \in C$,

$$
\begin{aligned}
& \left\|\mathrm{U}_{k} x-\mathrm{U}_{k} \mathrm{y}\right\|=\left\|\Pi_{\mathrm{C}}\left(\mathrm{I}-\lambda_{\mathrm{k}} \mathrm{F}\right) \mathrm{V}_{\mathrm{k}} \mathrm{G} x-\Pi_{\mathrm{C}}\left(\mathrm{I}-\lambda_{\mathrm{k}} \mathrm{F}\right) \mathrm{V}_{\mathrm{k}} \mathrm{Gy}\right\| \\
& \leqslant\left\|\left(I-\lambda_{k} F\right) V_{k} G x-\left(I-\lambda_{k} F\right) V_{k} G y\right\| \\
& \leqslant\left(1-\lambda_{k} \tau\right)\left\|V_{k} G x-V_{k} G y\right\| \\
& \leqslant\left(1-\lambda_{k} \tau\right)\|G x-G y\| \\
& \leqslant\left(1-\lambda_{k} \tau\right)\|x-y\| \text {, }
\end{aligned}
$$

where $\tau=1-\sqrt{\frac{1-\delta}{\zeta}} \in(0,1)$ (due to $\delta+\zeta>1$ ). From $\lambda_{k} \in(0,1]$, we get $1-\lambda_{k} \tau \in(0,1)$. So, $U_{k}$ is a contraction of $C$ into itself. By the Banach's Contraction Principle, there exists a unique element $x_{k} \in C$, satisfying (3.4).

Next, we divide the rest of the proof into several steps.

Step 1. We show that $\left\{x_{k}\right\}_{k=1}^{\infty}$ is bounded. Indeed, take an arbitrarily given $p \in \mathcal{F}$. Then we have $V_{k} p=p$ and $\mathrm{Gp}=\mathrm{p}$. Hence, by Lemma 2.13 (c) we get

$$
\begin{aligned}
\left\|x_{k}-p\right\| & =\left\|\Pi_{C}\left(I-\lambda_{k} F\right) V_{k} G x_{k}-p\right\| \\
& \leqslant\left\|\left(I-\lambda_{k} F\right) V_{k} G x_{k}-p\right\| \\
& =\left\|\left(I-\lambda_{k} F\right) V_{k} G x_{k}-\left(I-\lambda_{k} F\right) p-\lambda_{k} F(p)\right\| \\
& \leqslant\left(1-\lambda_{k} \tau\right)\left\|V_{k} G x_{k}-p\right\|+\lambda_{k}\|F(p)\| \\
& \leqslant\left(1-\lambda_{k} \tau\right)\left\|G x_{k}-p\right\|+\lambda_{k}\|F(p)\| \\
& \leqslant\left(1-\lambda_{k} \tau\right)\left\|x_{k}-p\right\|+\lambda_{k}\|F(p)\| .
\end{aligned}
$$

Therefore, $\left\|x_{k}-p\right\| \leqslant\|F(p)\| / \tau$, which implies the boundedness of $\left\{x_{k}\right\}_{k=1}^{\infty}$. So, the sequences $\left\{G x_{k}\right\}_{k=1}^{\infty}$, $\left\{\mathrm{V}_{\mathrm{k}} \mathrm{Gx}_{\mathrm{k}}\right\}_{\mathrm{k}=1}^{\infty}$, and $\left\{\mathrm{FV}_{\mathrm{k}} \mathrm{Gx}_{\mathrm{k}}\right\}_{\mathrm{k}=1}^{\infty}$ are also bounded. Since $\lambda_{\mathrm{k}} \rightarrow 0$, we get

$$
\left\|x_{k}-V_{k} G x_{k}\right\|=\left\|\Pi_{C}\left(I-\lambda_{k} F\right) V_{k} G x_{k}-V_{k} G x_{k}\right\| \leqslant\left\|\left(I-\lambda_{k} F\right) V_{k} G x_{k}-V_{k} G x_{k}\right\|=\lambda_{k}\left\|F\left(y_{k}\right)\right\| \rightarrow 0 .
$$

Step 2. We show that $\left\|x_{k}-G x_{k}\right\| \rightarrow 0$ as $k \rightarrow \infty$. Indeed, for simplicity, put $q=\Pi_{C}(p-\mu B p), u_{k}=$ $\Pi_{\mathrm{C}}\left(x_{k}-\mu \mathrm{B} x_{k}\right)$, and $v_{k}=\Pi_{C}\left(u_{k}-\lambda A u_{k}\right)$. Then $v_{k}=G x_{k}$ for all $k \geqslant 1$. From Proposition 2.5, we have

$$
\begin{aligned}
\left\|u_{k}-q\right\|^{2}=\left\|\Pi_{C}\left(x_{k}-\mu B x_{k}\right)-\Pi_{C}(p-\mu B p)\right\|^{2} & \leqslant\left\|x_{k}-p-\mu\left(B x_{k}-B p\right)\right\|^{2} \\
& \leqslant\left\|x_{k}-p\right\|^{2}-2 \mu\left(\beta-k^{2} \mu\right)\left\|B x_{k}-B p\right\|^{2}
\end{aligned}
$$


and

$$
\begin{aligned}
\left\|v_{k}-p\right\|^{2}=\left\|\Pi_{C}\left(u_{k}-\lambda A u_{k}\right)-\Pi_{C}(q-\lambda A q)\right\|^{2} & \leqslant\left\|u_{k}-q-\lambda\left(A u_{k}-A q\right)\right\|^{2} \\
& \leqslant\left\|u_{k}-q\right\|^{2}-2 \lambda\left(\alpha-k^{2} \lambda\right)\left\|A u_{k}-A q\right\|^{2} .
\end{aligned}
$$

Substituting (3.6) for (3.7), we obtain

$$
\left\|v_{k}-p\right\|^{2} \leqslant\left\|x_{k}-p\right\|^{2}-2 \mu\left(\beta-k^{2} \mu\right)\left\|B x_{k}-B p\right\|^{2}-2 \lambda\left(\alpha-k^{2} \lambda\right)\left\|A u_{k}-A q\right\|^{2} .
$$

From (3.5) and (3.8), we have

$$
\begin{aligned}
\left\|x_{k}-p\right\|^{2} & \leqslant\left[\left(1-\lambda_{k} \tau\right)\left\|G x_{k}-p\right\|+\lambda_{k}\|F(p)\|\right]^{2} \\
& =\left[\left(1-\lambda_{k} \tau\right)\left\|G x_{k}-p\right\|+\lambda_{k} \tau \frac{\|F(p)\|^{2}}{\tau}\right]^{2} \\
& \leqslant\left(1-\lambda_{k} \tau\right)\left\|G x_{k}-p\right\|^{2}+\lambda_{k} \frac{\|F(p)\|^{2}}{\tau} \\
& \leqslant\left\|G x_{k}-p\right\|^{2}+\lambda_{k} \frac{\|F(p)\|^{2}}{\tau} \\
& \leqslant\left\|x_{k}-p\right\|^{2}-2 \mu\left(\beta-k^{2} \mu\right)\left\|B x_{k}-B p\right\|^{2}-2 \lambda\left(\alpha-k^{2} \lambda\right)\left\|A u_{k}-A q\right\|^{2}+\lambda_{k} \frac{\|F(p)\|^{2}}{\tau},
\end{aligned}
$$

which immediately yields

$$
2 \mu\left(\beta-\kappa^{2} \mu\right)\left\|B x_{k}-B p\right\|^{2}+2 \lambda\left(\alpha-\kappa^{2} \lambda\right)\left\|A u_{k}-A q\right\|^{2} \leqslant \lambda_{k} \frac{\|F(p)\|^{2}}{\tau} .
$$

So, from $\lambda \in\left(0, \frac{\alpha}{\kappa^{2}}\right), \mu \in\left(0, \frac{\beta}{\kappa^{2}}\right)$, and $\lambda_{k} \rightarrow 0$ as $k \rightarrow \infty$, we deduce that

$$
\lim _{k \rightarrow \infty}\left\|B x_{k}-B p\right\|=0 \text { and } \lim _{k \rightarrow \infty}\left\|A u_{k}-A q\right\|=0 .
$$

Utilizing Proposition 2.1 and Lemma 2.3, we have

$$
\begin{aligned}
\left\|u_{k}-q\right\|^{2} & =\left\|\Pi_{C}\left(x_{k}-\mu B x_{k}\right)-\Pi_{C}(p-\mu B p)\right\|^{2} \\
& \leqslant\left\langle\left(x_{k}-\mu B x_{k}\right)-(p-\mu B p), j\left(u_{k}-q\right)\right\rangle \\
& =\left\langle\left(x_{k}-p, j\left(u_{k}-q\right)\right\rangle+\mu\left\langle B p-B x_{k}, j\left(u_{k}-q\right)\right\rangle\right. \\
& \leqslant \frac{1}{2}\left[\left\|x_{k}-p\right\|^{2}+\left\|u_{k}-q\right\|^{2}-g_{1}\left(\left\|x_{k}-u_{k}-(p-q)\right\|\right)\right]+\mu\left\|B p-B x_{k}\right\|\left\|u_{k}-q\right\|,
\end{aligned}
$$

which implies that

$$
\left\|u_{k}-q\right\|^{2} \leqslant\left\|x_{k}-p\right\|^{2}-g_{1}\left(\left\|x_{k}-u_{k}-(p-q)\right\|\right)+2 \mu\left\|B p-B x_{k}\right\|\left\|u_{k}-q\right\| .
$$

Similarly,

$$
\begin{aligned}
\left\|v_{k}-p\right\|^{2} & =\left\|\Pi_{C}\left(u_{k}-\lambda A u_{k}\right)-\Pi_{C}(q-\lambda A q)\right\|^{2} \\
& \leqslant\left\langle u_{k}-\lambda A u_{k}-(q-\lambda A q), j\left(v_{k}-p\right)\right\rangle \\
& =\left\langle u_{k}-q, j\left(v_{k}-p\right)\right\rangle+\lambda\left\langle A q-A u_{k}, j\left(v_{k}-p\right)\right\rangle \\
& \leqslant \frac{1}{2}\left[\left\|u_{k}-q\right\|^{2}+\left\|v_{k}-p\right\|^{2}-g_{2}\left(\left\|u_{k}-v_{k}+(p-q)\right\|\right)\right]+\lambda\left\|A q-A u_{k}\right\|\left\|v_{k}-p\right\|,
\end{aligned}
$$

which implies that

$$
\left\|v_{k}-p\right\|^{2} \leqslant\left\|u_{k}-q\right\|^{2}-g_{2}\left(\left\|u_{k}-v_{k}+(p-q)\right\|\right)+2 \lambda\left\|A q-A u_{k}\right\|\left\|v_{k}-p\right\| .
$$


Substituting (3.10) into (3.11), we get

$$
\begin{aligned}
\left\|v_{k}-p\right\|^{2} \leqslant & \left\|x_{k}-p\right\|^{2}-g_{1}\left(\left\|x_{k}-u_{k}-(p-q)\right\|\right)-g_{2}\left(\left\|u_{k}-v_{k}+(p-q)\right\|\right) \\
& +2 \mu\left\|B p-B x_{k}\right\|\left\|u_{k}-q\right\|+2 \lambda\left\|A q-A u_{k}\right\|\left\|v_{k}-p\right\| .
\end{aligned}
$$

From (3.5) and (3.12), we have

$$
\begin{aligned}
\left\|x_{k}-p\right\|^{2} \leqslant & {\left[\left(1-\lambda_{k} \tau\right)\left\|G x_{k}-p\right\|+\lambda_{k}\|F(p)\|\right]^{2} } \\
\leqslant & \left(1-\lambda_{k} \tau\right)\left\|G x_{k}-p\right\|^{2}+\lambda_{k} \frac{\|F(p)\|^{2}}{\tau} \\
\leqslant & \left\|G x_{k}-p\right\|^{2}+\lambda_{k} \frac{\|F(p)\|^{2}}{\tau} \\
\leqslant & \left\|x_{k}-p\right\|^{2}-g_{1}\left(\left\|x_{k}-u_{k}-(p-q)\right\|\right)-g_{2}\left(\left\|u_{k}-v_{k}+(p-q)\right\|\right) \\
& +2 \mu\left\|B p-B x_{k}\right\|\left\|u_{k}-q\right\|+2 \lambda\left\|A q-A u_{k}\right\|\left\|v_{k}-p\right\|+\lambda_{k} \frac{\|F(p)\|^{2}}{\tau}
\end{aligned}
$$

which hence leads to

$$
\begin{aligned}
& g_{1}\left(\left\|x_{k}-u_{k}-(p-q)\right\|\right)+g_{2}\left(\left\|u_{k}-v_{k}+(p-q)\right\|\right) \\
& \quad \leqslant 2 \mu\left\|B p-B x_{k}\right\|\left\|u_{k}-q\right\|+2 \lambda\left\|A q-A u_{k}\right\|\left\|v_{k}-p\right\|+\lambda_{k} \frac{\|F(p)\|^{2}}{\tau} .
\end{aligned}
$$

From (3.9), $\lambda_{k} \rightarrow 0$ as $k \rightarrow \infty$, and the boundedness of $\left\{u_{k}\right\}$ and $\left\{v_{k}\right\}$, we deduce that

$$
\lim _{k \rightarrow \infty} g_{1}\left(\left\|x_{k}-u_{k}-(p-q)\right\|\right)=0 \quad \text { and } \quad \lim _{k \rightarrow \infty} g_{2}\left(\left\|u_{k}-v_{k}+(p-q)\right\|\right)=0 .
$$

Utilizing the properties of $g_{1}$ and $g_{2}$, we conclude that

$$
\lim _{k \rightarrow \infty}\left\|x_{k}-u_{k}-(p-q)\right\|=0 \text { and } \lim _{k \rightarrow \infty}\left\|u_{k}-v_{k}+(p-q)\right\|=0 .
$$

From (3.13), we get

$$
\left\|x_{k}-v_{k}\right\| \leqslant\left\|x_{k}-u_{k}-(p-q)\right\|+\left\|u_{k}-v_{k}+(p-q)\right\| \rightarrow 0 \quad \text { as } k \rightarrow \infty .
$$

That is,

$$
\lim _{k \rightarrow \infty}\left\|x_{k}-G x_{k}\right\|=0 .
$$

This together with $\left\|x_{k}-V_{k} G x_{k}\right\| \rightarrow 0$, implies that

$$
\lim _{k \rightarrow \infty}\left\|x_{k}-y_{k}\right\|=0 \quad \text { and } \quad \lim _{k \rightarrow \infty}\left\|x_{k}-V_{k} x_{k}\right\|=0 .
$$

Step 3. We show that $\omega_{w}\left(x_{k}\right) \subset \mathcal{F}$, where

$$
\omega_{w}\left(x_{k}\right)=\left\{x \in C: x_{k_{i}} \rightarrow x \text { for some subsequences }\left\{x_{k_{i}}\right\} \text { of }\left\{x_{k}\right\}\right\} .
$$

Indeed, we first claim that $\left\|x_{k}-V x_{k}\right\| \rightarrow 0$ as $k \rightarrow \infty$. It can be readily seen from Lemma 3.3 that if $D$ is a nonempty and bounded subset of $X$, then, for $\varepsilon>0$, there exists $k_{0}>i$ such that for all $k>k_{0}$

$$
\sup _{x \in D}\left\|V_{k}^{i} G x-V_{\infty}^{i} G x\right\| \leqslant \varepsilon .
$$

Taking $D=\left\{x_{k}: k \geqslant 1\right\}$ and $i=1$, we have

$$
\left\|V_{k} G x_{k}-V G x_{k}\right\| \leqslant \sup _{x \in D}\left\|V_{k} G x-V G x\right\| \leqslant \varepsilon .
$$


So, it follows that

$$
\lim _{k \rightarrow \infty}\left\|V_{k} G x_{k}-V G x_{k}\right\|=0
$$

Similarly, by Proposition 3.2, we also have

$$
\lim _{k \rightarrow \infty}\left\|V_{k} x_{k}-V x_{k}\right\|=0
$$

Since $V_{k}$ is nonexpansive for all $k \geqslant 1, V$ is a nonexpansive self-mapping on $C$, and hence $V \circ G$ is also a nonexpansive self-mapping on $C$. Noting that

$$
\begin{aligned}
\left\|(V \circ G) x_{k}-V x_{k}\right\| & \leqslant\left\|V G x_{k}-V_{k} G x_{k}\right\|+\left\|V_{k} G x_{k}-V x_{k}\right\| \\
& \leqslant\left\|V G x_{k}-V_{k} G x_{k}\right\|+\left\|V_{k} G x_{k}-V_{k} x_{k}\right\|+\left\|V_{k} x_{k}-V x_{k}\right\| \\
& \leqslant\left\|V G x_{k}-V_{k} G x_{k}\right\|+\left\|G x_{k}-x_{k}\right\|+\left\|V_{k} x_{k}-V x_{k}\right\|,
\end{aligned}
$$

from (3.14), (3.16), and (3.17), we obtain that

$$
\lim _{k \rightarrow \infty}\left\|(\mathrm{V} \circ \mathrm{G}) \mathrm{x}_{\mathrm{k}}-\mathrm{V} \mathrm{x}_{\mathrm{k}}\right\|=0
$$

Also, noting that $\left\|x_{k}-V x_{k}\right\| \leqslant\left\|x_{k}-V_{k} x_{k}\right\|+\left\|V_{k} x_{k}-V x_{k}\right\|$, from (3.15) and (3.17), we get

$$
\lim _{k \rightarrow \infty}\left\|x_{k}-V x_{k}\right\|=0,
$$

which together with (3.18), leads to

$$
\lim _{k \rightarrow \infty}\left\|x_{k}-(V \circ G) x_{k}\right\|=0,
$$

Since $X$ is reflexive, there exists at lease a weak convergence subsequence of $\left\{x_{k}\right\}$, and hence $\omega_{w}\left(x_{k}\right) \neq \emptyset$. Take an arbitrary $p \in \omega_{w}\left(x_{k}\right)$. Then there exists a subsequence $\left\{x_{k_{i}}\right\}$ of $\left\{x_{k}\right\}$ such that $x_{k_{i}} \rightarrow p$. Since $X$ is uniformly convex and $\mathrm{V}$ and $\mathrm{G}$ are two nonexpansive self-mappings on $\mathrm{C}$, by Lemma 2.11 we know that $p \in \operatorname{Fix}(V \circ G)=\mathcal{F}$ (due to Lemma 3.4). This shows that $\omega_{w}\left(x_{k}\right) \subset \mathcal{F}$.

Step 4. We show that $\omega_{w}\left(x_{k}\right)=\omega_{s}\left(x_{k}\right)$, where

$$
\omega_{s}\left(x_{k}\right)=\left\{x \in C: x_{k_{i}} \rightarrow x \text { for some subsequences }\left\{x_{k_{i}}\right\} \text { of }\left\{x_{k}\right\}\right\} \text {. }
$$

Indeed, by Step 3 we know that $\omega_{w}\left(x_{k}\right) \subset \mathcal{F}$. Take an arbitrary $p \in \omega_{w}\left(x_{k}\right)$. Then there exists a subsequence $\left\{x_{k_{i}}\right\}$ of $\left\{x_{k}\right\}$ such that $x_{k_{i}} \rightarrow p$. Utilizing (3.4) and Lemmas 2.3 and 2.13 (c), we have

$$
\begin{aligned}
\left\|x_{k}-p\right\|^{2} & =\left\langle x_{k}-p, j\left(x_{k}-p\right)\right\rangle \\
& =\left\langle x_{k}-\left(I-\lambda_{k} F\right) y_{k}, j\left(x_{k}-p\right)\right\rangle+\left\langle\left(I-\lambda_{k} F\right) y_{k}-p, j\left(x_{k}-p\right)\right\rangle \\
& =\left\langle\Pi_{C}\left(I-\lambda_{k} F\right) y_{k}-\left(I-\lambda_{k} F\right) y_{k}, j\left(\Pi_{C}\left(I-\lambda_{k} F\right) y_{k}-p\right)\right\rangle+\left\langle\left(I-\lambda_{k} F\right) y_{k}-p, j\left(x_{k}-p\right)\right\rangle \\
& \leqslant\left\langle\left(I-\lambda_{k} F\right) y_{k}-p, j\left(x_{k}-p\right)\right\rangle \\
& =\left\langle\left(I-\lambda_{k} F\right) y_{k}-\left(I-\lambda_{k} F\right) p, j\left(x_{k}-p\right)\right\rangle-\lambda_{k}\left\langle F(p), j\left(x_{k}-p\right)\right\rangle \\
& \leqslant\left\|\left(I-\lambda_{k} F\right) y_{k}-\left(I-\lambda_{k} F\right) p\right\|\left\|x_{k}-p\right\|-\lambda_{k}\left\langle F(p), j\left(x_{k}-p\right)\right\rangle \\
& \leqslant\left(1-\lambda_{k} \tau\right)\left\|y_{k}-p\right\|\left\|x_{k}-p\right\|-\lambda_{k}\left\langle F(p), j\left(x_{k}-p\right)\right\rangle \\
& =\left(1-\lambda_{k} \tau\right)\left\|V_{k} G x_{k}-p\right\|\left\|x_{k}-p\right\|-\lambda_{k}\left\langle F(p), j\left(x_{k}-p\right)\right\rangle \\
& \leqslant\left(1-\lambda_{k} \tau\right)\left\|x_{k}-p\right\|^{2}-\lambda_{k}\left\langle F(p), j\left(x_{k}-p\right)\right\rangle,
\end{aligned}
$$

where $\tau=1-\sqrt{\frac{1-\delta}{\zeta}} \in(0,1)$. It turns out that

$$
\left\|x_{k}-p\right\|^{2} \leqslant \frac{1}{\tau}\left\langle F(p), j\left(p-x_{k}\right)\right\rangle .
$$


Thus, we can substitute $x_{k_{i}}$ for $x_{k}$ in (3.19) to get

$$
\left\|x_{k_{i}}-p\right\|^{2} \leqslant \frac{1}{\tau}\left\langle F(p), j\left(p-x_{k_{i}}\right)\right\rangle .
$$

Consequently, the weak convergence of $\left\{x_{k_{i}}\right\}$ to $p$ together with (3.20), actually implies that $x_{k_{i}} \rightarrow p$ as $i \rightarrow \infty$, and hence $p \in \omega_{s}\left(x_{k}\right)$. This shows that $\omega_{w}\left(x_{k}\right)=\omega_{s}\left(x_{k}\right)$.

Step 5. We show that each $p \in \omega_{s}\left(x_{k}\right)$ solves the variational inequality (3.3). Indeed, from (3.4), we have

$$
\begin{aligned}
x_{k} & =\Pi_{C}\left(I-\lambda_{k} F\right) y_{k}-\left(I-\lambda_{k} F\right) y_{k}+\left(I-\lambda_{k} F\right) y_{k} \\
& \Rightarrow x_{k}=\Pi_{C}\left(I-\lambda_{k} F\right) y_{k}-\left(I-\lambda_{k} F\right) y_{k}-\left(\left(I-\lambda_{k} F\right) x_{k}-\left(I-\lambda_{k} F\right) y_{k}\right)+x_{k}-\lambda_{k} F\left(x_{k}\right) \\
& \Rightarrow F\left(x_{k}\right)=\frac{1}{\lambda_{k}}\left[\Pi_{C}\left(I-\lambda_{k} F\right) y_{k}-\left(I-\lambda_{k} F\right) y_{k}-\left(\left(I-\lambda_{k} F\right) x_{k}-\left(I-\lambda_{k} F\right) y_{k}\right)\right] .
\end{aligned}
$$

Hence, utilizing (3.4) and Lemma 2.13 (c) we obtain that for each $z \in \mathcal{F}$,

$$
\begin{aligned}
\left\langle F\left(x_{k}\right), j\left(x_{k}-z\right)\right\rangle= & \frac{1}{\lambda_{k}}\left\langle\Pi_{C}\left(I-\lambda_{k} F\right) y_{k}-\left(I-\lambda_{k} F\right) y_{k}, j\left(x_{k}-z\right)\right\rangle \\
& -\frac{1}{\lambda_{k}}\left\langle\left(I-\lambda_{k} F\right) x_{k}-\left(I-\lambda_{k} F\right) y_{k}, j\left(x_{k}-z\right)\right\rangle \\
= & \frac{1}{\lambda_{k}}\left\langle\Pi_{C}\left(I-\lambda_{k} F\right) y_{k}-\left(I-\lambda_{k} F\right) y_{k}, j\left(\Pi_{C}\left(I-\lambda_{k} F\right) y_{k}-z\right)\right\rangle \\
& -\frac{1}{\lambda_{k}}\left\langle\left(I-\lambda_{k} F\right) x_{k}-\left(I-\lambda_{k} F\right) y_{k}, j\left(x_{k}-z\right)\right\rangle \\
\leqslant & -\frac{1}{\lambda_{k}}\left\langle\left(I-\lambda_{k} F\right) x_{k}-\left(I-\lambda_{k} F\right) y_{k}, j\left(x_{k}-z\right)\right\rangle \\
= & -\frac{1}{\lambda_{k}}\left\langle x_{k}-y_{k}, j\left(x_{k}-z\right)\right\rangle+\left\langle F\left(x_{k}\right)-F\left(y_{k}\right), j\left(x_{k}-z\right)\right\rangle \\
\leqslant & -\frac{1}{\lambda_{k}}\left\langle x_{k}-y_{k}, j\left(x_{k}-z\right)\right\rangle+\left\|F\left(x_{k}\right)-F\left(y_{k}\right)\right\|\left\|x_{k}-z\right\| .
\end{aligned}
$$

Now we claim that $\left\langle\left(I-\lambda_{k} F\right) x_{k}-\left(I-\lambda_{k} F\right) y_{k}, j\left(x_{k}-z\right)\right\rangle \leqslant 0$. Indeed, we can write $y_{k}=V_{k} G x_{k}$. At the same time, we note that $z=V_{k} G z$. So,

$$
\left\langle x_{k}-y_{k}, j\left(x_{k}-z\right)\right\rangle=\left\langle x_{k}-V_{k} G x_{k}-\left(z-V_{k} G z\right), j\left(x_{k}-z\right)\right\rangle .
$$

Since $I-V_{k} G$ is accretive (due to the nonexpansivity of $V_{k} G$ ), we deduce immediately that

$$
\left\langle x_{k}-y_{k}, j\left(x_{k}-z\right)\right\rangle=\left\langle x_{k}-V_{k} G x_{k}-\left(z-V_{k} G z\right), j\left(x_{k}-z\right)\right\rangle \geqslant 0 .
$$

Furthermore, utilizing Lemma 2.13 (a), we get $\left\|F\left(x_{k}\right)-F\left(y_{k}\right)\right\| \leqslant\left(1+\frac{1}{\zeta}\right)\left\|x_{k}-y_{k}\right\|$. Thus, it follows from (3.21) that

$$
\left\langle F\left(x_{k}\right), j\left(x_{k}-z\right)\right\rangle \leqslant\left(1+\frac{1}{\zeta}\right)\left\|x_{k}-y_{k}\right\|\left\|x_{k}-z\right\| .
$$

Since $F$ is $\delta$-strongly accretive, we have

$$
0 \leqslant \delta\left\|x_{k}-z\right\|^{2} \leqslant\left\langle F\left(x_{k}\right)-F(z), j\left(x_{k}-z\right)\right\rangle .
$$

Therefore,

$$
\left\langle F(z), j\left(x_{k}-z\right)\right\rangle \leqslant\left\langle F\left(x_{k}\right), j\left(x_{k}-z\right)\right\rangle .
$$

Combining (3.22) and (3.23), we get

$$
\left\langle F(z), j\left(x_{k}-z\right)\right\rangle \leqslant\left(1+\frac{1}{\zeta}\right)\left\|x_{k}-y_{k}\right\|\left\|x_{k}-z\right\| .
$$


Take an arbitrary $p \in \omega_{s}\left(x_{k}\right)$. Then there exists a subsequence $\left\{x_{k_{i}}\right\}$ of $\left\{x_{k}\right\}$ such that $x_{k_{i}} \rightarrow p$ as $i \rightarrow \infty$. According to Steps 3 and 4 , we know that $p \in \omega_{s}\left(x_{k}\right)\left(=\omega_{w}\left(x_{k}\right) \subset \mathcal{F}\right)$. Replacing $x_{k}$ in (3.24) with $x_{k_{i}}$, and noticing that as $i \rightarrow \infty, x_{k_{i}}-y_{k_{i}} \rightarrow 0$ (due to (3.15)), we have the Minty type variational inequality

$$
\langle\mathrm{F}(z), \mathrm{j}(\mathrm{p}-z)\rangle \leqslant 0, \quad \forall z \in \mathcal{F},
$$

which is equivalent to the variational inequality (see Lemma 2.12)

$$
\langle F(p), j(p-z)\rangle \leqslant 0, \quad \forall z \in \mathcal{F} .
$$

That is, $p \in \mathcal{F}$ is a solution of (3.3).

Step 6. We show that $\left\{x_{k}\right\}$ converges strongly to a unique solution in $\mathcal{F}$ to the VI (3.3). Indeed, we first claim that the solution set of (3.3) is a singleton. Indeed, assume that $\bar{p} \in \mathcal{F}$ is also a solution of (3.3). Then, we have

$$
\langle F(\bar{p}), j(\bar{p}-p)\rangle \leqslant 0
$$

Note that

$$
\langle F(p), j(p-\bar{p})\rangle \leqslant 0 .
$$

So, by the $\delta$-strong accretiveness of $F$, we have

$$
\langle F(\bar{p}), j(\bar{p}-p)\rangle+\langle F(p), j(p-\bar{p})\rangle \leqslant 0 \Rightarrow\langle F(\bar{p})-F(p), j(\bar{p}-p)\rangle \leqslant 0 \Rightarrow \delta\|\bar{p}-p\|^{2} \leqslant 0 .
$$

Therefore, $\bar{p}=p$. In summary, we have shown that each cluster point of $\left\{x_{k}\right\}$ (as $k \rightarrow \infty$ ) equals to $p$. Consequently, $x_{k} \rightarrow p$ as $k \rightarrow \infty$.

Theorem 3.6. Let $\mathrm{C}, \mathrm{X}, \Pi_{\mathrm{C}}, \mathrm{A}, \mathrm{B}, \mathrm{F},\left\{\mathrm{T}_{i}\right\}_{i=1}^{\infty}, \mathcal{F}, \delta, \zeta, \lambda$, and $\mu$ be as in Theorem 3.5. Let $\left\{\mathrm{V}_{\mathrm{k}}\right\}_{\mathrm{k}=1}^{\infty}$ be defined by (2.9) and (2.10). Let $\left\{x_{k}\right\}_{k=1}^{\infty}$ be defined by

$$
x_{k}=\gamma_{k} \Pi_{C}\left(I-\lambda_{k} F\right) x_{k}+\left(1-\gamma_{k}\right) V_{k} \Pi_{C}(I-\lambda A) \Pi_{C}(I-\mu B) x_{k}, \quad \forall k \geqslant 1,
$$

where $\left\{\gamma_{k}\right\}$ and $\left\{\lambda_{k}\right\}$ are sequences in $(0,1]$ such that $\lambda_{k} \rightarrow 0$ and $\gamma_{k} \rightarrow 0$ as $k \rightarrow \infty$. Then $\left\{x_{k}\right\}_{k=1}^{\infty}$ converges strongly to a unique solution $x^{*} \in \mathcal{F}$ to the VI (3.3).

Proof. Let the mapping $\mathrm{G}: \mathrm{C} \rightarrow \mathrm{C}$ be defined as $\mathrm{G}:=\Pi_{\mathrm{C}}(\mathrm{I}-\lambda \mathrm{A}) \Pi_{\mathrm{C}}(\mathrm{I}-\mu \mathrm{B})$, where $0<\lambda<\frac{\alpha}{\kappa^{2}}$ and $0<\mu<\frac{\beta}{\kappa^{2}}$. Note that

$$
x_{k}=\gamma_{k} \Pi_{C}\left(I-\lambda_{k} F\right) x_{k}+\left(1-\gamma_{k}\right) V_{k} G x_{k}, \quad \forall k \geqslant 1 .
$$

Consider the mapping $\mathrm{U}_{k} x=\gamma_{k} \Pi_{C}\left(I-\lambda_{k} F\right) x+\left(1-\gamma_{k}\right) V_{k} G x$ for all $k \geqslant 1$ and $x \in C$. Then, from Lemma 2.13 (c), we have that for all $x, y \in C$

$$
\begin{aligned}
& \left\|\mathrm{U}_{k} x-\mathrm{U}_{k} \mathrm{y}\right\|=\left\|\gamma_{k} \Pi_{\mathrm{C}}\left(\mathrm{I}-\lambda_{\mathrm{k}} \mathrm{F}\right) x+\left(1-\gamma_{\mathrm{k}}\right) \mathrm{V}_{\mathrm{k}} \mathrm{G} x-\left[\gamma_{\mathrm{k}} \Pi_{\mathrm{C}}\left(\mathrm{I}-\lambda_{\mathrm{k}} \mathrm{F}\right) \mathrm{y}+\left(1-\gamma_{\mathrm{k}}\right) \mathrm{V}_{\mathrm{k}} \mathrm{G} \mathrm{y}\right]\right\| \\
& =\left\|\gamma_{k}\left[\Pi_{C}\left(I-\lambda_{k} F\right) x-\Pi_{C}\left(I-\lambda_{k} F\right) y\right]+\left(1-\gamma_{k}\right)\left[V_{k} G x-V_{k} G y\right]\right\| \\
& \leqslant \gamma_{k}\left\|\Pi_{C}\left(I-\lambda_{k} F\right) x-\Pi_{C}\left(I-\lambda_{k} F\right) y\right\|+\left(1-\gamma_{k}\right)\left\|V_{k} G x-V_{k} G y\right\| \\
& \leqslant \gamma_{k}\left\|\left(I-\lambda_{k} F\right) x-\left(I-\lambda_{k} F\right) y\right\|+\left(1-\gamma_{k}\right)\|G x-G y\| \\
& \leqslant \gamma_{k}\left(1-\lambda_{k} \tau\right)\|x-y\|+\left(1-\gamma_{k}\right)\|x-y\|=\left(1-\gamma_{k} \lambda_{k} \tau\right)\|x-y\|
\end{aligned}
$$

with $\gamma_{k} \lambda_{k} \tau \in(0,1)$. So, $U_{k}$ is a contraction on C. By the Banach's Contraction Principle, there exists a unique element $x_{k} \in C$ such that $x_{k}=U_{k} x_{k}$; that is, there exists a unique element $x_{k} \in C$, satisfying (3.25).

Next, we divide the rest of the proof into several steps. 
Step 1. We show that $\left\{x_{k}\right\}_{k=1}^{\infty}$ is bounded. Indeed, take an arbitrarily given $p \in \mathcal{F}$. Then we have $V_{k} p=p$ and $\mathrm{Gp}=\mathrm{p}$. Hence, by Lemma 2.13 (c) we get

$$
\begin{aligned}
\left\|x_{k}-p\right\|^{2} & =\left\|\gamma_{k} \Pi_{C}\left(I-\lambda_{k} F\right) x_{k}+\left(1-\gamma_{k}\right) V_{k} G x_{k}-p\right\|^{2} \\
& \leqslant \gamma_{k}\left\|\Pi_{C}\left(I-\lambda_{k} F\right) x_{k}-p\right\|^{2}+\left(1-\gamma_{k}\right)\left\|V_{k} G x_{k}-p\right\|^{2} \\
& \leqslant \gamma_{k}\left\|\left(I-\lambda_{k} F\right) x_{k}-p\right\|^{2}+\left(1-\gamma_{k}\right)\left\|G x_{k}-p\right\|^{2} \\
& =\gamma_{k}\left\|\left(I-\lambda_{k} F\right) x_{k}-\left(I-\lambda_{k} F\right) p-\lambda_{k} F(p)\right\|^{2}+\left(1-\gamma_{k}\right)\left\|G x_{k}-p\right\|^{2} \\
& \leqslant \gamma_{k}\left[\left(1-\lambda_{k} \tau\right)\left\|x_{k}-p\right\|+\lambda_{k}\|F(p)\|\right]^{2}+\left(1-\gamma_{k}\right)\left\|G x_{k}-p\right\|^{2} \\
& \leqslant \gamma_{k}\left[\left(1-\lambda_{k} \tau\right)\left\|x_{k}-p\right\|^{2}+\lambda_{k} \tau^{-1}\|F(p)\|^{2}\right]+\left(1-\gamma_{k}\right)\left\|G x_{k}-p\right\|^{2} \\
& \leqslant \gamma_{k}\left(1-\lambda_{k} \tau\right)\left\|x_{k}-p\right\|^{2}+\gamma_{k} \lambda_{k} \tau^{-1}\|F(p)\|^{2}+\left(1-\gamma_{k}\right)\left\|x_{k}-p\right\|^{2} \\
& =\left(1-\gamma_{k} \lambda_{k} \tau\right)\left\|x_{k}-p\right\|^{2}+\gamma_{k} \lambda_{k} \tau^{-1}\|F(p)\|^{2} .
\end{aligned}
$$

Therefore, $\left\|x_{k}-p\right\| \leqslant\|F(p)\| / \tau$, which implies the boundedness of $\left\{x_{k}\right\}_{k=1}^{\infty}$. So, the sequences $\left\{G x_{k}\right\}_{k=1}^{\infty}$, $\left\{V_{k} G x_{k}\right\}_{k=1}^{\infty}$, and $\left\{F\left(x_{k}\right)\right\}_{k=1}^{\infty}$ are also bounded. Observe that

$$
\begin{aligned}
\left\|x_{k}-V_{k} G x_{k}\right\|=\gamma_{k}\left\|\Pi_{C}\left(I-\lambda_{k} F\right) x_{k}-V_{k} G x_{k}\right\| & \leqslant \gamma_{k}\left\|x_{k}-V_{k} G x_{k}-\lambda_{k} F\left(x_{k}\right)\right\| \\
& \leqslant \gamma_{k}\left\|x_{k}-V_{k} G x_{k}\right\|+\gamma_{k}\left\|F\left(x_{k}\right)\right\|,
\end{aligned}
$$

which implies that $\left\|x_{k}-V_{k} G x_{k}\right\| \leqslant \gamma_{k}\left\|F\left(x_{k}\right)\right\| /\left(1-\gamma_{k}\right)$. Since $\gamma_{k} \rightarrow 0$ and $\left\{F\left(x_{k}\right)\right\}$ is bounded, $\| x_{k}-$ $\mathrm{V}_{\mathrm{k}} \mathrm{G} \mathrm{x}_{\mathrm{k}} \| \rightarrow 0$ as $\mathrm{k} \rightarrow \infty$.

Step 2. We show that $\left\|x_{k}-G x_{k}\right\| \rightarrow 0$ as $k \rightarrow \infty$. Indeed, for simplicity, put $q=\Pi_{C}(p-\mu B p), u_{k}=$ $\Pi_{\mathrm{C}}\left(x_{k}-\mu B x_{k}\right)$, and $v_{k}=\Pi_{C}\left(u_{k}-\lambda A u_{k}\right)$. Then $v_{k}=G x_{k}$ for all $k \geqslant 1$. By the same arguments as those of (3.8), we obtain

$$
\left\|v_{k}-p\right\|^{2} \leqslant\left\|x_{k}-p\right\|^{2}-2 \mu\left(\beta-k^{2} \mu\right)\left\|B x_{k}-B p\right\|^{2}-2 \lambda\left(\alpha-k^{2} \lambda\right)\left\|A u_{k}-A q\right\|^{2} .
$$

Combining (3.26) and (3.27), we have

$$
\begin{aligned}
\left\|x_{k}-p\right\|^{2} \leqslant & \gamma_{k}\left[\left(1-\lambda_{k} \tau\right)\left\|x_{k}-p\right\|^{2}+\lambda_{k} \tau^{-1}\|F(p)\|^{2}\right]+\left(1-\gamma_{k}\right)\left\|G x_{k}-p\right\|^{2} \\
\leqslant & \gamma_{k}\left[\left\|x_{k}-p\right\|^{2}+\tau^{-1}\|F(p)\|^{2}\right]+\left(1-\gamma_{k}\right)\left[\left\|x_{k}-p\right\|^{2}-2 \mu\left(\beta-k^{2} \mu\right)\left\|B x_{k}-B p\right\|^{2}\right. \\
& \left.-2 \lambda\left(\alpha-k^{2} \lambda\right)\left\|A u_{k}-A q\right\|^{2}\right] \\
= & \left\|x_{k}-p\right\|^{2}+\gamma_{k} \tau^{-1}\|F(p)\|^{2}-2\left(1-\gamma_{k}\right)\left[\mu\left(\beta-k^{2} \mu\right)\left\|B x_{k}-B p\right\|^{2}+\lambda\left(\alpha-k^{2} \lambda\right)\left\|A u_{k}-A q\right\|^{2}\right],
\end{aligned}
$$

which immediately leads to

$$
2\left(1-\gamma_{k}\right)\left[\mu\left(\beta-k^{2} \mu\right)\left\|B x_{k}-B p\right\|^{2}+\lambda\left(\alpha-k^{2} \lambda\right)\left\|A u_{k}-A q\right\|^{2}\right] \leqslant \gamma_{k} \tau^{-1}\|F(p)\|^{2} .
$$

Since $\lambda \in\left(0, \frac{\alpha}{k^{2}}\right), \mu \in\left(0, \frac{\beta}{k^{2}}\right)$, and $\gamma_{k} \rightarrow 0$ as $k \rightarrow \infty$, we deduce that

$$
\lim _{k \rightarrow \infty}\left\|B x_{k}-B p\right\|=0 \text { and } \lim _{k \rightarrow \infty}\left\|A u_{k}-A q\right\|=0 .
$$

By the same arguments as those of (3.12), we get

$$
\begin{aligned}
\left\|v_{k}-p\right\|^{2} \leqslant & \left\|x_{k}-p\right\|^{2}-g_{1}\left(\left\|x_{k}-u_{k}-(p-q)\right\|\right)-g_{2}\left(\left\|u_{k}-v_{k}+(p-q)\right\|\right) \\
& +2 \mu\left\|B p-B x_{k}\right\|\left\|u_{k}-q\right\|+2 \lambda\left\|A q-A u_{k}\right\|\left\|v_{k}-p\right\| .
\end{aligned}
$$

Combining (3.26) and (3.29), we have

$$
\begin{aligned}
\left\|x_{k}-p\right\|^{2} \leqslant & \gamma_{k}\left[\left(1-\lambda_{k} \tau\right)\left\|x_{k}-p\right\|^{2}+\lambda_{k} \tau^{-1}\|F(p)\|^{2}\right]+\left(1-\gamma_{k}\right)\left\|G x_{k}-p\right\|^{2} \\
\leqslant & \gamma_{k}\left[\left\|x_{k}-p\right\|^{2}+\tau^{-1}\|F(p)\|^{2}\right]+\left(1-\gamma_{k}\right)\left[\left\|x_{k}-p\right\|^{2}-g_{1}\left(\left\|x_{k}-u_{k}-(p-q)\right\|\right)\right. \\
& \left.-g_{2}\left(\left\|u_{k}-v_{k}+(p-q)\right\|\right)+2 \mu\left\|B p-B x_{k}\right\|\left\|u_{k}-q\right\|+2 \lambda\left\|A q-A u_{k}\right\|\left\|v_{k}-p\right\|\right] \\
\leqslant & \left\|x_{k}-p\right\|^{2}+\gamma_{k} \tau^{-1}\|F(p)\|^{2}-\left(1-\gamma_{k}\right)\left[g_{1}\left(\left\|x_{k}-u_{k}-(p-q)\right\|\right)\right. \\
& \left.+g_{2}\left(\left\|u_{k}-v_{k}+(p-q)\right\|\right)\right]+2 \mu\left\|B p-B x_{k}\right\|\left\|u_{k}-q\right\|+2 \lambda\left\|A q-A u_{k}\right\|\left\|v_{k}-p\right\|,
\end{aligned}
$$


which immediately yields

$$
\begin{aligned}
& \left(1-\gamma_{k}\right)\left[g_{1}\left(\left\|x_{k}-u_{k}-(p-q)\right\|\right)+g_{2}\left(\left\|u_{k}-v_{k}+(p-q)\right\|\right)\right] \\
& \quad \leqslant \gamma_{k} \tau^{-1}\|F(p)\|^{2}+2 \mu\left\|B p-B x_{k}\right\|\left\|u_{k}-q\right\|+2 \lambda\left\|A q-A u_{k}\right\|\left\|v_{k}-p\right\| .
\end{aligned}
$$

Since $\gamma_{k} \rightarrow 0$ as $k \rightarrow \infty$, and $\left\{u_{k}\right\}$ and $\left\{v_{k}\right\}$ are bounded, we deduce from (3.28) that

$$
\lim _{k \rightarrow \infty} g_{1}\left(\left\|x_{k}-u_{k}-(p-q)\right\|\right)=0 \quad \text { and } \quad \lim _{k \rightarrow \infty} g_{2}\left(\left\|u_{k}-v_{k}+(p-q)\right\|\right)=0 .
$$

Utilizing the properties of $g_{1}$ and $g_{2}$, we conclude that

$$
\lim _{k \rightarrow \infty}\left\|x_{k}-u_{k}-(p-q)\right\|=0 \quad \text { and } \quad \lim _{k \rightarrow \infty}\left\|u_{k}-v_{k}+(p-q)\right\|=0 .
$$

From (3.30), we get

$$
\left\|x_{k}-v_{k}\right\| \leqslant\left\|x_{k}-u_{k}-(p-q)\right\|+\left\|u_{k}-v_{k}+(p-q)\right\| \rightarrow 0 \quad \text { as } k \rightarrow \infty .
$$

That is,

$$
\lim _{k \rightarrow \infty}\left\|x_{k}-G x_{k}\right\|=0 .
$$

This together with $\left\|x_{k}-V_{k} G x_{k}\right\| \rightarrow 0$, implies that

$$
\lim _{k \rightarrow \infty}\left\|x_{k}-y_{k}\right\|=0 \quad \text { and } \quad \lim _{k \rightarrow \infty}\left\|x_{k}-V_{k} x_{k}\right\|=0 .
$$

Step 3. We show that $\omega_{w}\left(x_{k}\right) \subset \mathcal{F}$, where

$$
\omega_{w}\left(x_{k}\right)=\left\{x \in C: x_{k_{i}} \rightarrow x \text { for some subsequences }\left\{x_{k_{i}}\right\} \text { of }\left\{x_{k}\right\}\right\} .
$$

Indeed, by the same arguments as those of Step 3 in the proof of Theorem 3.5, we can obtain $\omega_{w}\left(x_{k}\right) \subset \mathcal{F}$.

Step 4. We show that $\omega_{w}\left(x_{k}\right)=\omega_{s}\left(x_{k}\right)$, where

$$
\omega_{s}\left(x_{k}\right)=\left\{x \in C: x_{k_{i}} \rightarrow x \text { for some subsequences }\left\{x_{k_{i}}\right\} \text { of }\left\{x_{k}\right\}\right\} \text {. }
$$

Indeed, by Lemma 3.1, we have $\left\|V_{k} G x_{k}-z\right\| \leqslant\left\|x_{k}-z\right\|$ for any fixed $z \in \mathcal{F}$, and hence

$$
\begin{aligned}
\left\|x_{k}-z\right\|^{2}= & \left\|\gamma_{k} \Pi_{C}\left(I-\lambda_{k} F\right) x_{k}+\left(1-\gamma_{k}\right) V_{k} G x_{k}-z\right\|^{2} \\
= & \gamma_{k}\left[\left\langle\Pi_{C}\left(I-\lambda_{k} F\right) x_{k}-\left(I-\lambda_{k} F\right) x_{k}, j\left(x_{k}-z\right)\right\rangle\right. \\
& \left.+\left\langle\lambda_{k}(I-F) x_{k}+\left(1-\lambda_{k}\right) x_{k}-z, j\left(x_{k}-z\right)\right\rangle\right]+\left(1-\gamma_{k}\right)\left\langle V_{k} G x_{k}-z, j\left(x_{k}-z\right)\right\rangle \\
= & \gamma_{k}\left[\left\langle\Pi_{C}\left(I-\lambda_{k} F\right) x_{k}-\left(I-\lambda_{k} F\right) x_{k}, j\left(\Pi_{C}\left(I-\lambda_{k} F\right) x_{k}-z\right)\right\rangle\right. \\
& +\left\langle\Pi_{C}\left(I-\lambda_{k} F\right) x_{k}-\left(I-\lambda_{k} F\right) x_{k}, j\left(x_{k}-z\right)-j\left(\Pi_{C}\left(I-\lambda_{k} F\right) x_{k}-z\right)\right\rangle \\
& \left.+\left\langle\lambda_{k}(I-F) x_{k}+\left(1-\lambda_{k}\right) x_{k}-z, j\left(x_{k}-z\right)\right\rangle\right]+\left(1-\gamma_{k}\right)\left\langle V_{k} G x_{k}-z, j\left(x_{k}-z\right)\right\rangle \\
\leqslant & \gamma_{k}\left[\left\|\Pi_{C}\left(I-\lambda_{k} F\right) x_{k}-\left(I-\lambda_{k} F\right) x_{k}\right\|\left\|j\left(x_{k}-z\right)-j\left(\Pi_{C}\left(I-\lambda_{k} F\right) x_{k}-z\right)\right\|\right. \\
& \left.+\left\langle\lambda_{k}(I-F) x_{k}+\left(1-\lambda_{k}\right) x_{k}-z, j\left(x_{k}-z\right)\right\rangle\right]+\left(1-\gamma_{k}\right)\left\langle V_{k} G x_{k}-z, j\left(x_{k}-z\right)\right\rangle \\
\leqslant & \gamma_{k}\left[\left\|\Pi_{C}\left(I-\lambda_{k} F\right) x_{k}-\left(I-\lambda_{k} F\right) x_{k}\right\|\left\|j\left(x_{k}-z\right)-j\left(\Pi_{C}\left(I-\lambda_{k} F\right) x_{k}-z\right)\right\|\right. \\
& \left.+\lambda_{k}\left\langle(I-F) x_{k}-z, j\left(x_{k}-z\right)\right\rangle+\left(1-\lambda_{k}\right)\left\|x_{k}-z\right\|^{2}\right]+\left(1-\gamma_{k}\right)\left\|x_{k}-z\right\|^{2} \\
\leqslant & \gamma_{k}\left(\left\|\Pi_{C}\left(I-\lambda_{k} F\right) x_{k}-x_{k}\right\|+\lambda_{k}\left\|F\left(x_{k}\right)\right\|\right)\left\|j\left(x_{k}-z\right)-j\left(\Pi_{C}\left(I-\lambda_{k} F\right) x_{k}-z\right)\right\| \\
& +\gamma_{k} \lambda_{k}\left\langle(I-F) x_{k}-z, j\left(x_{k}-z\right)\right\rangle+\left(1-\gamma_{k} \lambda_{k}\right)\left\|x_{k}-z\right\|^{2} \\
\leqslant & 2 \gamma_{k} \lambda_{k}\left\|F\left(x_{k}\right)\right\|\left\|j\left(x_{k}-z\right)-j\left(\Pi \Pi_{C}\left(I-\lambda_{k} F\right) x_{k}-z\right)\right\| \\
& +\gamma_{k} \lambda_{k}\left\langle(I-F) x_{k}-(I-F) z-F(z), j\left(x_{k}-z\right)\right\rangle+\left(1-\gamma_{k} \lambda_{k}\right)\left\|x_{k}-z\right\|^{2} .
\end{aligned}
$$


Therefore, by Lemma $2.13(\mathrm{~b})$ we get

$$
\left\|x_{k}-z\right\|^{2} \leqslant(1-\tau)\left\|x_{k}-z\right\|^{2}-\left\langle F(z), j\left(x_{k}-z\right)\right\rangle+2\left\|F\left(x_{k}\right)\right\|\left\|j\left(x_{k}-z\right)-j\left(\Pi_{C}\left(I-\lambda_{k} F\right) x_{k}-z\right)\right\|,
$$

which immediately leads to

$$
\left\|x_{k}-z\right\|^{2} \leqslant \frac{1}{\tau}\left(\left\langle F(z), j\left(z-x_{k}\right)\right\rangle+2\left\|F\left(x_{k}\right)\right\|\left\|j\left(x_{k}-z\right)-j\left(\Pi_{C}\left(I-\lambda_{k} F\right) x_{k}-z\right)\right\|\right), \quad \forall z \in \mathcal{F},
$$

where $\tau=1-\sqrt{\frac{1-\delta}{\zeta}} \in(0,1)$. Note that the uniform smoothness of $X$ guarantees the uniform continuity of $j$ on every nonempty bounded subset of $X$. Hence it is easy to see that

$$
\lim _{k \rightarrow \infty}\left\|j\left(x_{k}-z\right)-j\left(\Pi_{C}\left(I-\lambda_{k} F\right) x_{k}-z\right)\right\|=0 .
$$

Now, take an arbitrary $p \in \omega_{w}\left(x_{k}\right)$. Then there exists a subsequence $\left\{x_{k_{i}}\right\}$ of $\left\{x_{k}\right\}$ such that $x_{k_{i}} \rightarrow p$. In terms of Step 3, we know that $p \in \omega_{w}\left(x_{k}\right) \subset \mathcal{F}$. Thus, we can substitute $x_{k_{i}}$ for $x_{k}$ and $p$ for $z$ in (3.31) to get

$$
\left\|x_{k_{i}}-p\right\|^{2} \leqslant \frac{1}{\tau}\left(\left\langle F(p), j\left(p-x_{k_{i}}\right)\right\rangle+2\left\|F\left(x_{k_{i}}\right)\right\|\left\|j\left(x_{k_{i}}-p\right)-j\left(\Pi_{C}\left(I-\lambda_{k_{i}} F\right) x_{k_{i}}-p\right)\right\|\right) .
$$

Consequently, the weak convergence of $\left\{x_{k_{i}}\right\}$ to $p$ together with (3.32), actually implies that $x_{k_{i}} \rightarrow p$ as $i \rightarrow \infty$, and hence $p \in \omega_{s}\left(x_{k}\right)$. This shows that $\omega_{w}\left(x_{k}\right)=\omega_{s}\left(x_{k}\right)$.

Step 5. We show that each $p \in \omega_{s}\left(x_{k}\right)$ solves the variational inequality (3.3). Indeed, take an arbitrary $p \in \omega_{s}\left(x_{k}\right)$. Then there exists a subsequence $\left\{x_{k_{i}}\right\}$ of $\left\{x_{k}\right\}$ such that $x_{k_{i}} \rightarrow p$ as $i \rightarrow \infty$. According to Steps 3 and 4 , we know that $p \in \omega_{s}\left(x_{k}\right)\left(=\omega_{w}\left(x_{k}\right) \subset \mathcal{F}\right)$. Replacing $x_{k}$ in (3.32) with $x_{k_{i}}$, and noticing that $x_{k_{i}} \rightarrow p$, we have the Minty type variational inequality

$$
\langle\mathrm{F}(z), \mathrm{j}(z-\mathrm{p})\rangle \leqslant 0, \quad \forall z \in \mathcal{F},
$$

which is equivalent to the variational inequality (see Lemma 2.12)

$$
\langle F(p), j(p-z)\rangle \leqslant 0, \quad \forall z \in \mathcal{F} .
$$

That is, $p \in \mathcal{F}$ is a solution of (3.3).

Step 6. We show that $\left\{x_{k}\right\}$ converges strongly to a unique solution in $\mathcal{F}$ to the VI (3.3). Indeed, by the same arguments as those of Step 6 in the proof of Theorem 3.5, we derive the desired conclusion. This completes the proof.

\section{Acknowledgment}

This research was partially supported by the Innovation Program of Shanghai Municipal Education Commission (15ZZ068), Ph.D. Program Foundation of Ministry of Education of China (20123127110002) and Program for Outstanding Academic Leaders in Shanghai City (15XD1503100). Yeong-Cheng Liou was supported in part by the grand form Kaohsiung Medical University Research Foundation (KMU-Q106005) and Taiwan-Russian joint grant MOST 106-2923-E-039-001-MY3.

\section{References}

[1] Q. H. Ansari, J.-C. Yao, Systems of generalized variational inequalities and their applications, Appl. Anal., 76 (2000), 203-217. 1

[2] K. Aoyama, H. Iiduka, W. Takahashi, Weak convergence of an iterative sequence for accretive operators in Banach spaces, Fixed Point Theory Appl., 2006 (2006), 13 pages. 1

[3] F. E. Browder, Nonexpansive nonlinear operators in a Banach space, Proc. Nat. Acad. Sci. U.S.A., 54 (1965), $1041-1044$. 2.11 
[4] N. Buong, N. T. H. Phuong, Strong convergence to solutions for a class of variational inequalities in Banach spaces by implicit iteration methods, J. Optim. Theory Appl., 159 (2013), 399-411. 2

[5] N. Buong, N. T. Quynh Anh, An implicit iteration method for variational inequalities over the set of common fixed points for a finite family of nonexpansive mappings in Hilbert spaces, Fixed Point Theory Appl., 2011 (2011), 10 pages. 1, 2, 2, 3.2

[6] L.-C. Ceng, Q. H. Ansari, J.-C. Yao, Mann-type steepest-descent and modified hybrid steepest-descent methods for variational inequalities in Banach spaces, Numer. Funct. Anal. Optim., 29 (2008), 987-1033. 1, 2, 2.9

[7] L.-C. Ceng, H. Gupta, Q. H. Ansari, Implicit and explicit algorithms for a system of nonlinear variational inequalities in Banach spaces, J. Nonlinear Convex Anal., 16 (2015), 965-984. 1, 1, 2, 2.7, 2, 2.13

[8] L.-C. Ceng, S.-M. Guu, J.-C. Yao, Hybrid iterative method for finding common solutions of generalized mixed equilibrium and fixed point problems, Fixed Point Theory Appl., 2012 (2012), 19 pages. 1

[9] L.-C. Ceng, A. Petrussel, J.-C. Yao, Implicit iteration scheme with perturbed mapping for common fixed points of a finite family of Lipschitz pseudocontractive mappings, J. Math. Inequal., 1 (2007), 243-258. 1

[10] L.-C. Ceng, C.-Y. Wang, J.-C. Yao, Strong convergence theorems by a relaxed extragradient method for a general system of variational inequalities, Math. Methods Oper. Res., 67 (2008), 375-390. 1

[11] S. Y. Cho, B. A. Bin Dehaish, X.-L. Qin, Weak convergence of a splitting algorithm in Hilbert spaces, J. Appl. Anal. Comput., 7 (2017), 427-438. 1

[12] I. Cioranescu, Geometry of Banach spaces, duality mappings and nonlinear problems, Mathematics and its Applications, Kluwer Academic Publishers Group, Dordrecht, (1990). 1

[13] A. N. Iusem, B. F. Svaiter, A variant of Korpelevich's method for variational inequalities with a new search strategy, Optimization, 42 (1997), 309-321. 1

[14] S. Kamimura, W. Takahashi, Strong convergence of a proximal-type algorithm in a Banach space, SIAM J. Optim., 13 (2002), 938-945. 2.1

[15] M. Kikkawa, W. Takahashi, Strong convergence theorems by the viscosity approximation method for a countable family of nonexpansive mappings, Taiwanese J. Math., 12 (2008), 583-598. 2

[16] G. M. Korpelevič, An extragradient method for finding saddle points and for other problems, (Russian) Ékonom. i Mat. Metody, 12 (1976), 747-756. 1

[17] X.-L. Qin, S. Y. Cho, Convergence analysis of a monotone projection algorithm in reflexive Banach spaces, Acta Math. Sci. Ser. B Engl. Ed., 37 (2017), 488-502. 1

[18] S. Reich, Weak convergence theorems for nonexpansive mappings in Banach spaces, J. Math. Anal. Appl., 67 (1979), 274-276. 2.3

[19] M. V. Solodov, B. F. Svaiter, A new projection method for variational inequality problems, SIAM J. Control Optim., 37 (1999), 765-776. 1

[20] W. Takahashi, Weak and strong convergence theorems for families of nonexpansive mappings and their applications, Proceedings of Workshop on Fixed Point Theory, Kazimierz Dolny, (1997), Ann. Univ. Mariae Curie-Skodowska Sect. A, 51 (1997), 277-292. 2

[21] Y. Takahashi, K. Hashimoto, M. Kato, On sharp uniform convexity, smoothness, and strong type, cotype inequalities, J. Nonlinear Convex Anal., 3 (2002), 267-281. 2

[22] R. U. Verma, On a new system of nonlinear variational inequalities and associated iterative algorithms, Math. Sci. Res. Hot-Line, 3 (1999), 65-68. 1

[23] H.-K. Xu, Inequalities in Banach spaces with applications, Nonlinear Anal., 16 (1991), 1127-1138. 2.2

[24] Y.-H. Yao, R.-D. Chen, H.-K. Xu, Schemes for finding minimum-norm solutions of variational inequalities, Nonlinear Anal., 72 (2010), 3447-3456. 1

[25] Y.-H. Yao, Y.-C. Liou, S. M. Kang, Approach to common elements of variational inequality problems and fixed point problems via a relaxed extragradient method, Comput. Math. Appl., 59 (2010), 3472-3480. 1

[26] Y.-H. Yao, Y.-C. Liou, S. M. Kang, Y.-L. Yu, Algorithms with strong convergence for a system of nonlinear variational inequalities in Banach spaces, Nonlinear Anal., 74 (2011), 6024-6034. 2.3

[27] Y.-H. Yao, Y.-.C Liou, J.-C. Yao, Iterative algorithms for the split variational inequality and fixed point problems under nonlinear transformations, J. Nonlinear Sci. Appl., 10 (2017), 843-854. 2.4, 2.6, 2.12

[28] Y.-H. Yao, M. A. Noor, Y.-C. Liou, Strong convergence of a modified extragradient method to the minimum-norm solution of variational inequalities, Abstr. Appl. Anal., 2012 (2012), 9 pages. 2.5

[29] Y.-H. Yao, M. A. Noor, Y.-C. Liou, S. M. Kang, Iterative algorithms for general multivalued variational inequalities, Abstr. Appl. Anal., 2012 (2012), 10 pages. 1

[30] Y.-H. Yao, M. Postolache, Y.-C. Liou, Z.-S. Yao, Construction algorithms for a class of monotone variational inequalities, Optim. Lett., 10 (2016), 1519-1528.

[31] H. Zegeye, N. Shahzad, Y.-H. Yao, Minimum-norm solution of variational inequality and fixed point problem in Banach spaces, Optimization, 64 (2015), 453-471. 1

[32] L.-C. Zeng, J.-C. Yao, Implicit iteration scheme with perturbed mapping for common fixed points of a finite family of nonexpansive mappings, Nonlinear Anal., 64 (2006), 2507-2515. 1, 2, 2.8 